\title{
The Effect of Teratozoospermia on Sex Chromosomes in Human Embryos
}

This article was published in the following Dove Press journal:

The Application of Clinical Genetics

\author{
Dalia Mostafa Nayel' \\ Hanan Salah El Din Mahrous' \\ Emad El Din Khalifa ${ }^{2}$ \\ Soha Kholeif' \\ Ghada Mohamed Elhady (D) \\ 'Department of Human Genetics, \\ Medical Research Institute, Alexandria \\ University, Alexandria, Egypt; \\ ${ }^{2}$ Department of Obstetrics and \\ Gynecology, Faculty of Medicine, \\ Alexandria University, Alexandria, Egypt
}

Correspondence: Ghada Mohamed

Elhady

Department of Human Genetics, Medical

Research Institute, Alexandria University,

Alexandria, Egypt

Email ghada.alhadi@alexu.edu.eg
Purpose: The aim of this study is to evaluate the effect of abnormal semen morphology on the frequency of sex chromosomal abnormalities in embryos obtained by ICSI, which represents the first to be studied in Egyptian population.

Methods: Forty-two couples suffering from male infertility due to teratozoospermia were divided into two groups: patients with severe and moderate teratozoospermia (group A and B, respectively). All involved couples were subjected to careful history taking and had a normal clinical examination and karyotype. Females were subjected to hormonal assays, pelvic ultrasound, hysterosalpingography and yielded normal results, while male partners were subjected to computerized semen analysis. Preimplantation genetic diagnosis was performed for all suitably developed embryos including embryo biopsy, fixation of biopsied cells and fluorescent in situ hybridization (FISH) analysis.

Results: Couples included in the two groups were found to be homogenous in terms of age of both partners and duration of infertility. Interpretation of FISH results was performed by evaluation of embryos' chromosomal constitution as regards abnormalities in chromosomes $\mathrm{X}, \mathrm{Y}$ and 18 . Twenty-seven embryos $(48.2 \%)$ were found chromosomally abnormal in group A, while only 14 embryos (25.0\%) were found chromosomally abnormal in group B. Aneuploidies involved only sex chromosomes were tripled in group A embryos when compared to their frequency in group B embryos $(26.8 \%$ and $8.3 \%$, respectively) with statistically significant difference between the two groups $(\mathrm{p}=0.002)$. Monosomies were the most common type of aneuploidy and were significantly higher in group A (14.3\%) when compared to group B $(3.6 \%)(\mathrm{p}=0.047)$. Embryos with mosaic abnormalities were more common in group A (12.5\%) when compared to group B $(3.6 \%)$, however not statistically significantly different $(p=0.162)$. A significant difference between the two studied groups as regards the total number of potentially viable chromosomal abnormalities detected and the potentially viable sex chromosomal aneuploidies detected $(\mathrm{p}<0.001$ and $\mathrm{p}=0.002)$, respectively.

Conclusion: The cases with severe teratozoospermia undergoing ICSI treatment can display a higher rate of sex chromosome aneuploidies in their embryos (threefold) than cases with moderate teratozoospermia.

Keywords: ICSI, teratozoospermia, aneuploidy, FISH

\section{Introduction}

Teratozoospermia is defined as the presence of spermatozoa with abnormal morphology, which may be associated with infertility and intracytoplasmic sperm injection (ICSI) is considered as the treatment of choice. Over the last decade, cytogenetic investigations of severe teratozoospermia represented one of the most productive areas in the field of male infertility and assisted conception. ${ }^{1-4}$ The 
effect of isolated teratozoospermia is controversial, with studies showing both improved ${ }^{5}$ and worsened ${ }^{6-9}$ assisted reproductive technology (ART) fertilization and/or pregnancy rates with in vitro fertilization outcome (IVF).

Some studies expected that sperm morphology did not indicate chromosomal material, and ICSI was possible even if no spermatozoa with normal morphology were found. ${ }^{10,11}$ However, other investigators stated an inverse relationship between sperm aneuploidy and the percentage of normal forms. ${ }^{12,13}$ Härkönen et $\mathrm{al}^{13}$ reported that patients with severe teratozoospermia (normal forms $10 \%$ ) have a sperm aneuploidy rate significantly higher frequency than that found in patients with a less marked degree of teratozoospermia. In addition, reports based on prenatal diagnosis in ICSI pregnancies have indicated an increased risk of sex chromosomal and autosomal trisomies that were shown to be of paternal origin. ${ }^{14-16}$

Fluorescent in situ hybridization technique (FISH) represents a very straightforward technique that essentially consists of hybridizing a DNA probe to its complementary sequence on chromosomal preparations previously fixed on slides, which has been used to detect aneuploidy frequencies in cells. FISH gives the ability to quantify both autosomes and sex chromosomes and consequently the detection of cells characterized by an increased frequency of aneuploidy. ${ }^{17,18}$

No technique currently exists that allows detection of chromosomal status of a single spermatozoon and consequently use for microinjection, since current analysis requires fixation and $\mathrm{FISH}$, which make the spermatozoa non-viable and therefore not suitable for ICSI. Preimplantation genetic diagnosis (PGD) in conjunction with ICSI has been developed to detect genetic abnormalities in early embryos before pregnancy is established ${ }^{19}$ including aneuploidy and single gene defects in an effort to avoid the transfer of affected embryos. PGD includes the molecular analysis of one or more biopsied cells from a 3-day or 5-day old embryo using FISH technique ${ }^{20}$ in order to potentially improve ICSI outcomes in both infertile couples ${ }^{21}$ and also fertile couples who are at risk for particular genetic diseases. ${ }^{22}$ The aim of this study is to evaluate the effect of abnormal semen morphology on the frequency of sex chromosomal abnormalities in embryos obtained by ICSI, which represents the first to be studied in Egyptian population.

\section{Materials and Methods}

Forty-two normal karyotype infertile couples presenting to Dar El Khousoba infertility center, during the time period from June 2016 to August 2018, were included in the study. The study was conducted in accordance with the Declaration of Helsinki and an informed written consent was obtained from each couple who participated in the study.

Female partners were aged below 35 years; male partners were aged below 45 years, to avoid age-related aneuploidy. Abnormal sperm morphology (teratozoospermia) was the clinically apparent diagnosed attributing factor to the infertility problem of these couples and female partners were clinically free, to exclude female factor as a cause of infertility.

Couples with thyroid dysfunction, diabetes mellitus, autoimmune disorders, cancer, ovarian dysfunction, smoking or addiction were excluded from the study.

All involved couples were subjected to careful history taking and full clinical examination and karyotype and were found normal. Females were subjected to hormonal assays, pelvic ultrasound, hysterosalpingography and yielded normal results, while male partners were subjected to computerized semen analysis (CASA).

Teratozoospermia is defined as a percentage of normalshaped spermatozoa under the lesser reference limit. According to Kruger classification, ${ }^{23}$ severe teratozoospermia cut off value is normal spermatozoa under $4 \%$, while mild and moderate teratozoospermia cut off values were normal spermatozoa ranging from $4 \%$ to $14 \%$. Male partners had varying degrees of mild, moderate and severe teratozoospermia according to Kruger classification diagnosed after 2 consecutive semen analyses that are 2 weeks apart.

Twenty-two couples whose percentage of normal sperms in the ejaculate was less than $4 \%$ according to Kruger Strict criteria were included in group A, while twenty couples whose percentage of normal sperms in the ejaculate was ranging between $4 \%$ and $14 \%$ according to Kruger Strict criteria were included in group $\mathrm{B}^{23}$ A total of 145 embryos were biopsied from the 42 couples under study, 72 embryos were biopsied from 22 couples included in Group A, while 73 embryos were biopsied from 20 couples included in group B.

The minimal sample size was calculated based on a study aimed to analyze to what extent sperm aneuploidy is associated with sperm morphology and subsequently with embryo aneuploidy ${ }^{24}$ and on another study aimed to study the predictive value of strict sperm morphology for IVF outcomes. ${ }^{25}$ 
Kahraman, Findikli ${ }^{24}$ reported that 4 out of 97 (4.12\%) had sex chromosome aneuploidies, while Kiseleva, Abubakirov $^{25}$ found that $10.82 \%$ had sex chromosome aneuploidies. Assuming that Egyptian population may have the average of the two findings $(7.47 \%)$, a minimum sample size of 107 embryos for estimation of $\sim 7.5 \%$ prevalence for the present cross-sectional study, ${ }^{26,27}$ with a significance level of $95 \%$ (accepted alpha error of 0.05$)$ and $\pm 5 \%$ confidence interval $(5 \%$ Absolute precision). Sample size per group does not need to be increased to control for attrition bias. ${ }^{28}$

\section{Semen Sample Preparation}

Couples were instructed to abstain from sexual intercourse 2-3 days prior to the oocyte retrieval day (ovum pick up day; OPU). On the day of OPU, male partners were requested to collect a fresh semen sample into a sterile pot by masturbation. After liquefaction, fresh semen samples were double washed using HEPESbuffered culture media supplemented by human serum albumin. Culture media were warmed to $37 \mathrm{c}$ prior to use and semen samples were centrifuged using highdensity centrifugation.

Washed semen samples were analyzed using computer-aided semen analysis (CASA system) and detailed morphological assessment was performed according to Eliasson et $\mathrm{al}^{29}$ and using $4 \%$ as a cutoff value for defining severe teratozoospermia and $4-14 \%$ as the range of defining mild and moderate teratozoospermia.

\section{Ovulation Induction, Oocyte Retrieval, Embryo Transfer and Development}

Stimulation was performed using antagonist protocol in combination with recombinant FSH and HCG. Transvaginal follicle aspiration under complete anesthesia was performed. Approximately $2 \mathrm{~h}$ after oocyte retrieval, the cumulus and corona radiata were removed by brief exposure $(10 \mathrm{sec})$ to SAGE hyaluronidase containing $80 \mathrm{U} / \mathrm{mL}$ of bovine hyaluronidase in HEPES-HTF with $5 \mathrm{mg} / \mathrm{mL}$ human serum albumin and ICSI was applied to metaphase II (MII) with a motile normal headed spermatozoon that has been selected and immobilized by squeezing technique in a droplet of Polyvinylpyrrolidone (PVP) under an inverted microscope (Olympus inverted microscope, 200x). Immediately after ICSI, injected oocytes were transferred to the sequential media (Quinns advantage protein plus, SAGE) and cultured with this media until embryo transfer.

Fertilization was assessed $16-18 \mathrm{~h}$ after injection under inverted microscope and was considered normal when two distinct pronuclei containing precursor nucleolar bodies were present.

\section{Embryo Biopsy and FISH}

All suitably developed embryos with good morphology (grade I) were biopsied. Each embryo was held by a holding pipette, had an opening created in the zona pellucida (ZP) using the moveable Saturn 5 active laser system (Bickland industrial Park, Falmouth, Cornwall TR114TA, UK) and the single blastomere biopsy or the multiple cell trophoblast biopsy was then removed by gentle suction using a 30-40 um biopsy needle under the Olympus inverted microscope (x200 magnification). After the biopsy, embryos were cultured at least overnight to observe their development.

Embryo biopsy was then placed on a glass slide being observed using a stereomicroscope (Olympus SZ51) and rinsed in a drop of sodium bicarbonate based (not HEPES based) Ham's F10. Then, the embryo biopsy was placed on another glass slide and fixed with a drop of the fixative solution (Carnoy's fixative solution: freshly prepared mixture of 3 parts absolute methanol to 1 part glacial acetic acid that was kept cold in the freezer) until the biopsy was no longer seen, then its place was marked by a circle using a diamond marker.

The slides were then transported to the molecular laboratory of human genetics department at the medical research institute for the FISH procedure to be performed.

Slides were then incubated in $2 \times \mathrm{SSC} / 0.5 \% \mathrm{NP} 40$ or 2 $\mathrm{x}$ SSC, at RT for 2 minutes, then they were dehydrated through $70 \%, 90 \%$ and $100 \%$ ethanol series, 2 minutes each at room temperature (RT), then they were allowed to air dry. After initial denaturation for 5 minutes at $74^{\circ} \mathrm{C}$, the slides were hybridized with $10 \mu \mathrm{L}$ of probe mixture at $37^{\circ}$ $\mathrm{C}$ overnight. FISH technique was performed using a commercial probe that recognizes the alpha satellite DNA sequences at the DXZ1, DYZ3 and D18Z1 regions of the chromosome $\mathrm{X}, \mathrm{Y}$ and 18 , respectively. Chromosome 18 centromeric probe was used as reference signal in order to evaluate hybridization effciency. 
The slides were scanned under fluorescent microscope (Olympus/BX53) equipped with single band-pass filter (DAPI/Green, Red and Blue) which is designated to excite and transmit spectrum DAPI counterstain, spectrum green, spectrum red and spectrum. Image capture was done using Digital high-resolution camera (JENOPTIK:D-007739Jena) (Olympus, Japan) and the software Auto image analysis for FISH and karyotyping LLKIA. The results of hybridization were assessed by the number of signals in blastomeres' nuclei.

\section{Statistical Analysis of the Data}

Data were fed to the computer and analyzed using IBM SPSS software package version 20.0. (Armonk, NY: IBM Corp) Qualitative data were described using number and percent. The Kolmogorov-Smirnov test was used to verify the normality of distribution Quantitative data were described using range (minimum and maximum), mean and standard deviation. The significance of the obtained results was judged at the 5\% level. Chi-square test for categorical variables, to compare between different groups. Fisher's Exact correction for chi-square when more than $20 \%$ of the cells have expected count less than 5. The sample size was calculated according to Charan and Biswas (2013). ${ }^{30}$

\section{Results}

Couples included in the two groups were found to be homogenous in terms of age of both partners ranged from 21.0 to 34.0 years (mean $30.82 \pm 3.55$ ) for female partners and from 30.0 to 44.0 years (mean $40.0 \pm 4.36$ ) for male partners in group $\mathrm{A} /$ ranged from 21.0 to 34.0 years (mean $30.75 \pm 4.27$ ) for female partners and from 28.0 to 44.0 years (mean $37.50 \pm \pm 5.46$ ) for male partners in group B) and duration of infertility which was ranged from 1.50 to 12.0 years (mean $5.16 \pm 2.96$ ) in group $\mathrm{A}$ and from 1.0 to 14.0 years (mean $6.0 \pm \pm 3.55$ ) in group B.

\section{Clinical Outcome According to Semen Parameters}

All male partners included in the study had undergone a semen analysis of the semen sample obtained on the day of oocyte retrieval which was used to inject the oocytes. Semen analysis results of group A and group B patients were documented in Tables 1 and 2 respectively.
Table I Age and Semen Characteristics of Men Included in Group A

\begin{tabular}{|c|c|c|c|c|}
\hline $\begin{array}{l}\text { Patient } \\
\text { Number }\end{array}$ & $\begin{array}{c}\text { Male } \\
\text { Partners' } \\
\text { Age (Years) }\end{array}$ & $\begin{array}{c}\text { Normal } \\
\text { Sperm } \\
(\%)\end{array}$ & $\begin{array}{c}\text { Sperm } \\
\text { Concentration } \\
\left(\times 10^{6} \mathrm{~mL}\right)\end{array}$ & $\begin{array}{c}\text { Sperm } \\
\text { Motility } \\
\text { (\%) }\end{array}$ \\
\hline I & 30 & $0 \%$ & $0.1 \mathrm{mil} / \mathrm{mL}$ & $4 \%$ \\
\hline 2 & 41 & $2 \%$ & $4 \mathrm{mil} / \mathrm{mL}$ & $20 \%$ \\
\hline 3 & 44 & $4 \%$ & $19 \mathrm{mil} / \mathrm{mL}$ & $40 \%$ \\
\hline 4 & 34 & $4 \%$ & $4 \mathrm{mil} / \mathrm{mL}$ & $48 \%$ \\
\hline 5 & 40 & $3 \%$ & $7 \mathrm{mil} / \mathrm{mL}$ & $12 \% \%$ \\
\hline 6 & 32 & $4 \%$ & $26 \mathrm{mil} / \mathrm{mL}$ & $30 \%$ \\
\hline 7 & 35 & $4 \%$ & $85 \mathrm{mil} / \mathrm{mL}$ & $80 \%$ \\
\hline 8 & 34 & $4 \%$ & $25 \mathrm{mil} / \mathrm{mL}$ & $10 \%$ \\
\hline 9 & 36 & $4 \%$ & $10 \mathrm{mil} / \mathrm{mL}$ & $30 \%$ \\
\hline 10 & 43 & $1 \%$ & $0.4 \mathrm{mil} / \mathrm{mL}$ & $20 \%$ \\
\hline II & 41 & $3 \%$ & $4.5 \mathrm{mil} / \mathrm{mL}$ & $22 \%$ \\
\hline 12 & 44 & $4 \%$ & $16 \mathrm{mil} / \mathrm{mL}$ & $40 \%$ \\
\hline 13 & 42 & $4 \%$ & $2.4 \mathrm{mil} / \mathrm{mL}$ & $35 \%$ \\
\hline 14 & 43 & $3 \%$ & $0.2 \mathrm{mil} / \mathrm{mL}$ & $5 \%$ \\
\hline 15 & 40 & $4 \%$ & $17 \mathrm{mil} / \mathrm{mL}$ & $30 \%$ \\
\hline 16 & 42 & $3 \%$ & $5 \mathrm{mil} / \mathrm{mL}$ & $48 \%$ \\
\hline 17 & 44 & $2 \%$ & $54 \mathrm{mil} / \mathrm{mL}$ & $59 \%$ \\
\hline 18 & 43 & $4 \%$ & $100 \mathrm{mil} / \mathrm{mL}$ & $90 \%$ \\
\hline 19 & 43 & $2 \%$ & $138 \mathrm{mil} / \mathrm{mL}$ & $53 \%$ \\
\hline 20 & 43 & $4 \%$ & $5.6 \mathrm{mil} / \mathrm{mL}$ & $47 \%$ \\
\hline 21 & 44 & $4 \%$ & $27 \mathrm{mil} / \mathrm{mL}$ & $18 \%$ \\
\hline 22 & 42 & $3 \%$ & $22 \mathrm{mil} / \mathrm{mL}$ & $25 \%$ \\
\hline Range & $30.0-44.0$ & $0.0-4.0$ & $0.10-138.0$ & $4.0-82.0$ \\
\hline Mean & 40.0 & 3.36 & 26.01 & 34.90 \\
\hline SD & \pm 4.36 & \pm 1.05 & \pm 36.51 & \pm 22.44 \\
\hline
\end{tabular}

When evaluated according sperm concentrations, a significant difference was observed $(\mathrm{p}=0.019)$; the sperm concentrations ranged from 0.10 to $138.0 \mathrm{mil} / \mathrm{mL}$ (mean 26.01 \pm 36.51 ) in group A and from 2.70 to $141.0 \mathrm{mil} / \mathrm{mL}$ (mean $43.94 \pm 53.81)$ in group B male partners. On the other hand, sperm motility in both groups showed no significant difference $(\mathrm{p}=0.753$ ) and ranged from $4 \%$ to $90 \%$ (mean $34.82 \pm 22.44$ ) in group A male partners and from $4 \%$ to $82 \%$ (mean $34.90 \pm$ 
Table 2 Age and Semen Characteristics of Men Included in Group B

\begin{tabular}{|c|c|c|c|c|}
\hline Patient Number & Male Partners' Age (Years) & Normal Sperm (\%) & Sperm Concentration $\left(\times 10^{6} \mathrm{~mL}\right)$ & Sperm Motility (\%) \\
\hline 23 & 38 & $9.5 \%$ & $51 \mathrm{mil} / \mathrm{mL}$ & $33 \%$ \\
\hline 24 & 28 & $13 \%$ & $20 \mathrm{mil} / \mathrm{mL}$ & $53 \%$ \\
\hline 25 & 42 & $10 \%$ & $52 \mathrm{mil} / \mathrm{mL}$ & $23 \%$ \\
\hline 26 & 28 & $14 \%$ & $59 \mathrm{mil} / \mathrm{mL}$ & $40 \%$ \\
\hline 27 & 33 & $11 \%$ & $34 \mathrm{mil} / \mathrm{mL}$ & $43 \%$ \\
\hline 28 & 29 & $7.5 \%$ & $60 \mathrm{mil} / \mathrm{mL}$ & $23 \%$ \\
\hline 29 & 43 & $12 \%$ & $2.7 \mathrm{mil} / \mathrm{mL}$ & $24 \%$ \\
\hline 30 & 38 & $10 \%$ & II mil/mL & $82 \%$ \\
\hline 31 & 44 & $6 \%$ & $8 \mathrm{mil} / \mathrm{mL}$ & $5 \%$ \\
\hline 32 & 44 & $12 \%$ & $83 \mathrm{mil} / \mathrm{mL}$ & $33 \%$ \\
\hline 33 & 42 & $9 \%$ & $75 \mathrm{mil} / \mathrm{mL}$ & $40 \%$ \\
\hline 34 & 35 & $5 \%$ & $33 \mathrm{mil} / \mathrm{mL}$ & $8 \%$ \\
\hline 35 & 36 & $9 \%$ & $29 \mathrm{mil} / \mathrm{mL}$ & $5 \%$ \\
\hline 36 & 36 & $8 \%$ & $23 \mathrm{mil} / \mathrm{mL}$ & $42 \%$ \\
\hline 37 & 38 & $6 \%$ & $70 \mathrm{mil} / \mathrm{mL}$ & $40 \%$ \\
\hline 38 & 44 & $5.5 \%$ & $43 \mathrm{mil} / \mathrm{mL}$ & $32 \%$ \\
\hline 39 & 41 & $13 \%$ & $141 \mathrm{mil} / \mathrm{mL}$ & $61 \%$ \\
\hline 40 & 43 & $8 \%$ & $3 \mathrm{mil} / \mathrm{mL}$ & $4 \%$ \\
\hline 41 & 31 & $11 \%$ & $15 \mathrm{mil} / \mathrm{mL}$ & $47 \%$ \\
\hline 42 & 37 & $14 \%$ & $66 \mathrm{mil} / \mathrm{mL}$ & $60 \%$ \\
\hline Range & $28.0-44.0$ & $8.0-14.0$ & $2.70-141.0$ & $4.0-82.0$ \\
\hline Mean & 37.50 & 10.48 & 43.94 & 34.90 \\
\hline SD & \pm 5.46 & \pm 2.20 & \pm 33.81 & \pm 20.62 \\
\hline
\end{tabular}

20.62) in group B male partners as shown in Tables 1 and 2.

\section{Outcome According to Assisted Reproductive Treatment and ICSI Cycle Parameters}

Female partners included in the two groups were found to be homogenous as regards peak estradiol levels (E2) measured following ovulation induction treatment, 48 hours prior to oocyte retrieval. Female partners were also found to be homogenous with respect to the number of oocytes retrieved and the number of fertilized oocytes assessed 48 hours post injection as presented in Tables 3 and 4.
Eleven couples in group A had previous attempts ICSI cycles that ranged from 1 to 3 attempts (mean=). Only four couples of these have achieved pregnancy (36.4\%), three of which were ongoing pregnancies and one of them was aborted. Only six couples in group B had previous attempts of ICSI cycles that ranged from 1 to 3 (mean=). Only one couple achieved an ongoing pregnancy (16.7\%).

\section{Pre-Implantation Genetic Diagnosis (PGD) Outcome}

Following ovulation induction treatment, peak estradiol levels (E2) of all females. 
Table 3 Cycle Parameters and Assisted Reproductive Treatment Outcome of Patients Included in Group A

\begin{tabular}{|c|c|c|c|c|c|}
\hline $\begin{array}{l}\text { Patient } \\
\text { No. }\end{array}$ & $\begin{array}{c}\text { Maternal Age } \\
\text { (Years) }\end{array}$ & $\begin{array}{c}\text { Duration of Infertility } \\
\text { (Years) }\end{array}$ & $\begin{array}{c}\text { Peak } \\
\text { E2 pg/mL }\end{array}$ & $\begin{array}{l}\text { No. of Oocytes } \\
\text { Retrieved }\end{array}$ & $\begin{array}{l}\text { No. of Oocytes } \\
\text { Fertilized }\end{array}$ \\
\hline $\mathbf{I}$ & 25 & 5 & 3683 & 10 & 10 \\
\hline 2 & 33 & 6 & 8686 & 24 & 19 \\
\hline 3 & 32 & 4 & 6266 & 24 & 20 \\
\hline 4 & 27 & 2.5 & 2973 & 35 & 23 \\
\hline 5 & 31 & 4 & 7009 & 27 & 22 \\
\hline 6 & 21 & 3 & 4342 & 19 & 19 \\
\hline 7 & 29 & 2.5 & 4897 & 21 & 16 \\
\hline 8 & 27 & 7 & 6630 & 25 & 18 \\
\hline 9 & 34 & 1.5 & 4575 & 18 & 12 \\
\hline 10 & 29 & 5 & $517 \mid$ & 10 & 7 \\
\hline II & 27 & 9 & 6267 & 11 & 9 \\
\hline 12 & 34 & 2 & 2130 & 10 & 7 \\
\hline 13 & 34 & 10 & 9596 & 24 & 10 \\
\hline 14 & 33 & 8 & 7635 & 20 & 15 \\
\hline 15 & 30 & 2 & 3456 & 13 & 9 \\
\hline 16 & 32 & 3 & 5475 & 9 & 7 \\
\hline 17 & 33 & 9 & 3875 & 11 & 7 \\
\hline 18 & 34 & 3 & 4222 & 29 & 17 \\
\hline 19 & 34 & 5 & 5759 & 17 & 12 \\
\hline 20 & 33 & 12 & 7650 & 19 & 12 \\
\hline 21 & 32 & 3 & 6738 & 13 & 10 \\
\hline 22 & 34 & 7 & 2687 & 8 & 6 \\
\hline Range & $21.0-34.0$ & $1.50-12.0$ & $2130.0-9596.0$ & $8.0-35.0$ & $6.0-23.0$ \\
\hline Mean & 30.82 & 5.16 & 5441.91 & 18.05 & 13.05 \\
\hline $\begin{array}{l}\text { Standard } \\
\text { deviation }\end{array}$ & \pm 3.55 & \pm 2.96 & \pm 1981.35 & \pm 7.51 & \pm 5.36 \\
\hline
\end{tabular}

A total of 145 embryos were biopsied from the 42 couples under study, 72 embryos were biopsied from 22 couples included in Group A, while 73 embryos were biopsied from 20 couples included in group B.

Out of the 145 embryo biopsies taken, 33 embryo biopsies (16 embryo biopsies from 12 couples in group A and 17 embryo biopsies from 13 couples in group B) have failed to give an informative FISH result and were excluded from the cohort available for analysis. Both groups showed no significant difference as regards the number of failed embryo biopsies that constituted 22.2\% and $23.3 \%$ of group $\mathrm{A}$ and $\mathrm{B}$ embryos, respectively $(\mathrm{p}=0.643)$.

Embryo biopsies were retrieved either on the third or fifth day following oocyte injection. On the third day, biopsy only one or two cells were retrieved as embryo biopsy, while on fifth day, blastocyst biopsy multiple trophoblastic cells were retrieved for analysis. On classifying 
Table 4 Cycle Parameters and Assisted Reproductive Treatment Outcome of Patients Included in Group B

\begin{tabular}{|c|c|c|c|c|c|}
\hline No. & $\begin{array}{l}\text { Maternal Age } \\
\text { (Years) }\end{array}$ & $\begin{array}{c}\text { Duration of Infertility } \\
\text { (Years) }\end{array}$ & $\begin{array}{c}\text { Peak E2 pg/ } \\
\mathrm{mL}\end{array}$ & $\begin{array}{c}\text { No. of Oocytes } \\
\text { Retrieved }\end{array}$ & $\begin{array}{l}\text { No. of Oocytes } \\
\text { Fertilized }\end{array}$ \\
\hline 23 & 34 & 14 & 4329 & 19 & 19 \\
\hline 24 & 21 & I & 3191 & 13 & 13 \\
\hline 25 & 34 & 6 & 4279 & 17 & 17 \\
\hline 26 & 23 & 6 & 4538 & 12 & 12 \\
\hline 27 & 28 & 4 & 2467 & 8 & 8 \\
\hline 28 & 23 & 2 & 7576 & 16 & 16 \\
\hline 29 & 34 & 6 & 10,122 & 25 & 25 \\
\hline 30 & 31 & 4 & 2627 & 17 & 17 \\
\hline 31 & 33 & 13 & 10,205 & 33 & 33 \\
\hline 32 & 33 & 5 & 4896 & 10 & 10 \\
\hline 33 & 34 & 3 & 6837 & 13 & 13 \\
\hline 34 & 33 & 7 & 11,156 & 17 & 17 \\
\hline 35 & 32 & 5 & 3658 & 10 & 10 \\
\hline 36 & 32 & 5 & 4528 & 13 & 13 \\
\hline 37 & 34 & 12 & 5857 & 18 & 18 \\
\hline 38 & 34 & 9 & 7467 & 17 & 17 \\
\hline 39 & 33 & 3 & 6534 & 14 & 14 \\
\hline 40 & 34 & 7 & 3467 & 8 & 8 \\
\hline 41 & 26 & 5 & 8699 & 23 & 23 \\
\hline 42 & 29 & 3 & 9573 & 26 & 26 \\
\hline Range & $21.0-34.0$ & $1.0-14.0$ & $2467.0-11,156.0$ & $8.0-33.0$ & $6.0-28.0$ \\
\hline $\begin{array}{l}\text { Mean } \\
\text { Standard } \\
\text { deviation }\end{array}$ & $\begin{array}{r}30.75 \\
\pm 4.27\end{array}$ & $\begin{array}{r}6.0 \\
\pm 3.55\end{array}$ & $\begin{array}{r}6100.30 \\
\pm 2730.69\end{array}$ & $\begin{array}{r}16.45 \\
\pm 6.40\end{array}$ & $\begin{array}{r}13.70 \\
\pm 5.55\end{array}$ \\
\hline
\end{tabular}

the total number of embryos analyzed (112 embryos) according to the day on which the embryo biopsy was retrieved, it was found that embryo biopsies were retrieved from 88 embryos (78.6\%) and from 24 embryos (21.4\%) on day 5 and day 3 , respectively.

Out of the 22 cases included in group A, biopsies of only two couples were retrieved on day $3(9.1 \%)$, while the biopsies of the remaining 20 couples were retrieved on day 5 (90.9\%). In group B, biopsies of only 8 couples were retrieved on day $3(40 \%)$, while the biopsies of the remaining 12 couples were retrieved on day $5(60 \%)$
Failure rate of FISH procedure (non-informative embryo biopsies) was lower in the biopsies retrieved on day 5 when compared with biopsies retrieved on day 3 , although the difference was not statistically significant $(\mathrm{p}=0.647$ and $\mathrm{p}=0.326$ in group $\mathrm{A}$ and $\mathrm{B}$, respectively). Failure rate of FISH procedure constituted $28.6 \%$ of day 3 biopsies versus $21.5 \%$ of day 5 biopsies retrieved from group A patients, while constituted $29.6 \%$ of day 3 biopsies versus $19.6 \%$ of day 5 embryo biopsies in group B.

The frequencies of normal and abnormal embryos detected according to the day of biopsy in both groups 
revealed that the frequency of normal embryos was slightly higher in embryos whose biopsy was obtained on day 5 when compared with embryos whose biopsy was obtained on day $3(64.8 \%$ versus 62.5 , respectively) without statistical significant difference $(\mathrm{p}=837)$.

Interpretation of FISH results was performed by evaluation of embryos' chromosomal constitution as regards abnormalities in chromosomes X, Y and 18 (Table 5). On comparing chromosomal constitution of embryos in the two groups, FISH results revealed a significant difference between the two groups regarding the frequencies of chromosomally abnormal embryos $(\mathrm{p}=0.011)$. As, out of the 56 informative embryo biopsies evaluated from each group, 27 embryos (48.2\%) were found chromosomally abnormal in group A, while only 14 embryos $(25.0 \%)$ were found chromosomally abnormal in group B. Normal male and female patterns are illustrated in figure $1(\mathrm{~A}$

\section{\&B).}

On paying a particular attention to the aneuploid abnormalities which differed significantly between the two groups $(p=0.017)$, we found that aneuploidies detected mainly involved sex chromosomes and their frequency was tripled in group A embryos when compared to their frequency in group B embryos $(26.8 \%$ and $8.3 \%$, respectively) with a statistically significant difference between the two groups $(p=0.002)$. Frequencies of different types of aneuploidies detected in groups A and B are illustrated in figure 2 .

Regarding the type of aneuploidies detected, monosomies were the most common type of aneuploidy and were significantly higher in group A (14.3\%) when compared to group B (3.6\%) $(\mathrm{p}=0.047)$ (Figure 2$)$. All detected monosomies (eight embryos in group $\mathrm{A}$ and two embryos in group B) involved the $\mathrm{X}$ chromosome (Turner syndrome) (Figure 1D) with no detected monosomies in chromosome 18 or in the $\mathrm{Y}$ chromosome.

Trisomies were also more common in group A (12.5\%) when compared to group B $(3.6 \%)$ despite not statistically significantly different $(p=0.162)$ (Figure2). Trisomies were encountered in a total of seven embryos in group A, all of which involved sex chromosomes with no detected trisomy of chromosome 18 in group A embryos. However, trisomies were detected in only two embryos in group $\mathrm{B}$, one of which involved chromosome 18, while the other involved the Y chromosome (XYY). The incidence of XXY embryos (Figure 1C) was significantly higher in group $A(p=0.022)$ as the abnormality was detected in 5 embryos in group A $(8.9 \%)$, while it was not detected in any of group B embryos. The incidence of XYY embryos was similar in both groups with one embryo carrying the abnormality in each group $(p=1.000)$. The incidence of XXX embryos was higher in group $\mathrm{A}$ as the abnormality was detected in one embryo in group A (1.8\%), while it was not detected in any of group B embryos, although the difference was not statistically significant $(\mathrm{p}=1.000)$.

The number of embryos that showed nullisomy of sex chromosomes was detected in one embryo in group A $(1.8 \%)$ and in two embryos in group B (3.6\%) with no statistically significant difference between the two groups (Figure 2).

Haploidy was detected in 4 embryos $(7.1 \%)$ in group A and in 5 embryos $(8.9 \%)$ in group B. Tetraploidy was detected in only a single embryo in group B (1.8\%), while it was not detected in any of group A embryos (Table 5) (Figure 3).

Embryos carrying mosaic abnormalities (Figure 4 and 5) were more common in group A (12.5\%) when compared to group B $(3.6 \%)$, however not statistically significantly different $(p=0.162)$. The majority of the mosaic abnormalities detected were of the diploid mosaic type (8.9\% and $3.6 \%$ in group A and group B, respectively), while the total mosaic type was only detected in group A embryos (3.6\%) and was not detected in any of group B embryos; however, the difference was not statistically significant $(\mathrm{FEp}=0.438$ and $\mathrm{FEp}=0.495$, respectively) (Table 5).

\section{Correlation Between Viability of Embryos and Proportion of Normal/Abnormal Cells}

Chromosomal abnormalities detected were further classified according to whether they are potentially viable or potentially non-viable (incompatible with life and expected to abort) as presented in Tables 6 and 7. These data revealed a significant difference between the two studied groups as regards the total number of potentially viable chromosomal abnormalities detected and the potentially viable sex chromosomal aneuploidies detected ( $p<0.001$ and $p=0.002$, respectively). The total number of potentially viable chromosomal abnormalities was significantly higher in group A (39.3\%) when compared to group B $(10.7 \%)$. Also, the potentially viable sex chromosomal aneuploidies detected were significantly higher in group A $(26.8 \%)$ when compared to group B $(5.4 \%)$ as shown in Table 6 . 
Table 5 Comparison Between the Two Studied Groups According to Frequencies of Different Chromosomal Abnormalities Detected

\begin{tabular}{|c|c|c|c|c|c|}
\hline \multirow[t]{2}{*}{ Chromosomal Abnormalities Detected } & \multicolumn{2}{|c|}{$\begin{array}{c}\text { Group } \\
A(n=56)\end{array}$} & \multicolumn{2}{|c|}{$\begin{array}{c}\text { Group } \\
B(n=56)\end{array}$} & \multirow[t]{2}{*}{$\mathbf{P}$} \\
\hline & No. & $\%$ & No. & $\%$ & \\
\hline Total number & 27 & 48.2 & 14 & 25.0 & $0.011 *$ \\
\hline Polyploidies: & 4 & 7.1 & 6 & 10.7 & 0.508 \\
\hline Haploid & 4 & 7.1 & 5 & 8.9 & $\mathrm{FE}_{\mathrm{p}}=1.000$ \\
\hline Tetraploid & 0 & 0.0 & $\mathrm{I}$ & 1.8 & $\mathrm{FE}_{\mathrm{p}}=1.000$ \\
\hline Aneuploidies & 16 & 28.6 & 6 & 10.7 & $0.017^{*}$ \\
\hline Monosomies: & 8 & 14.3 & 2 & 3.6 & $0.047^{*}$ \\
\hline Turner syndrome & 8 & 14.3 & 2 & 3.6 & $0.047^{*}$ \\
\hline Trisomies: & 7 & 12.5 & 2 & 3.6 & $\mathrm{FE}_{\mathrm{p}}=0.162$ \\
\hline$X X Y$ & 5 & 8.9 & 0 & 0.0 & $0.022 *$ \\
\hline XYY & I & 1.8 & I & 1.8 & $\mathrm{FE}_{\mathrm{p}}=1.000$ \\
\hline$x X X$ & 1 & 1.8 & 0 & 0.0 & $\mathrm{FE}_{\mathrm{P}}=1.000$ \\
\hline Trisomy 18 & 0 & 0 & 1 & 1.8 & ${ }^{F E} E_{p}=1.000$ \\
\hline Nullisomy of sex chromosomes & I & 1.8 & 2 & 3.6 & $\mathrm{FE}_{\mathrm{p}}=1.000$ \\
\hline Complex Mosaic abnormalities & 7 & 12.5 & 2 & 3.6 & $\mathrm{FE}_{\mathrm{P}}=0.162$ \\
\hline Aneuploid mosaic abnormalities & 2 & 3.6 & 0 & 0.0 & $\mathrm{FE}_{\mathrm{p}}=0.495$ \\
\hline Mosaic; haploid and Turner syndrome & I & 1.8 & 0 & 0.0 & $\mathrm{FE}_{\mathrm{p}}=1.000$ \\
\hline Mosaic; $X X X X Y, X X Y$ & I & 1.8 & 0 & 0.0 & $\mathrm{FE}_{\mathrm{p}}=1.000$ \\
\hline Diploid mosaic abnormalities & 5 & 8.9 & 2 & 3.6 & $\mathrm{FE}_{\mathrm{p}}=0.438$ \\
\hline Diploid-aneuploid mosaics & 3 & 5.4 & 0 & 0.0 & $\mathrm{FE}_{\mathrm{P}}=0.243$ \\
\hline Mosaic; normal and Turner syndrome & 2 & 3.6 & 0 & 0.0 & $\mathrm{FE}_{\mathrm{P}}=0.495$ \\
\hline Mosaic; normal and Trisomy 18 & I & 1.8 & 0 & 0.0 & $\mathrm{FE}_{\mathrm{p}}=1.000$ \\
\hline \multicolumn{6}{|l|}{ Diploid-polyploid mosaics } \\
\hline Mosaic; normal and tetraploidy & I & 1.8 & 0 & 0.0 & $\mathrm{FE}_{\mathrm{p}}=1.000$ \\
\hline \multicolumn{6}{|l|}{ Diploid-polyploid-aneuploid mosaics } \\
\hline Mosaic; normal, tetraploid-aneuploid (72,XXXYYY), triploid-aneuploid (100,XXXXYYYY) & I & 1.8 & 0 & 0.0 & $\mathrm{FE}_{\mathrm{p}}=1.000$ \\
\hline Diploid-haploid mosaics & 0 & 0.0 & 2 & 3.6 & $\mathrm{FE}_{\mathrm{P}}=0.495$ \\
\hline Mosaic; normal and haploid & 0 & 0.0 & 2 & 3.6 & $\mathrm{FE}_{\mathrm{P}}=0.495$ \\
\hline
\end{tabular}

Notes: *Statistically significant at $\mathrm{p} \leq 0.05$. ${ }^{\mathrm{FE}} \mathrm{p}, \mathrm{p}$ value for Fisher Exact for Chi-square test for comparing between the two groups.

All diploid mosaic embryos detected had a percentage of abnormal cells less than $50 \%$ of the cells analyzed and were considered potentially viable, while in total mosaic embryos $100 \%$ of the cells analyzed were abnormal with at least $50 \%$ of which were compatible with life in their aneuploid form (turner mosaic and XXY,XXXXY mosaic) and were also considered viable. ${ }^{31}$

The total number of potentially viable mosaic abnormalities (based on the percentage of chromosomally abnormal cells detected as shown in Table 8) was markedly higher in group A (12.5\%) when compared to group B (3.6\%) although statistically non-significant $(\mathrm{p}=0.162)$ as shown in Table 6 .
There was also no significant difference between the two groups as regards the number of autosomal aneuploidies detected and the total number of potentially non-viable chromosomal abnormalities detected $(\mathrm{p}=1000$ and $\mathrm{p}=0.376$, respectively) as shown in Tables 6 and 7.

\section{Correlation Between Pre-Implantation Genetic Diagnosis Outcome and the Day of Biopsy}

Embryo biopsies were retrieved either on the third or fifth day following oocyte injection. On third day, biopsy only one or two cells were retrieved as embryo biopsy, while on fifth day, 


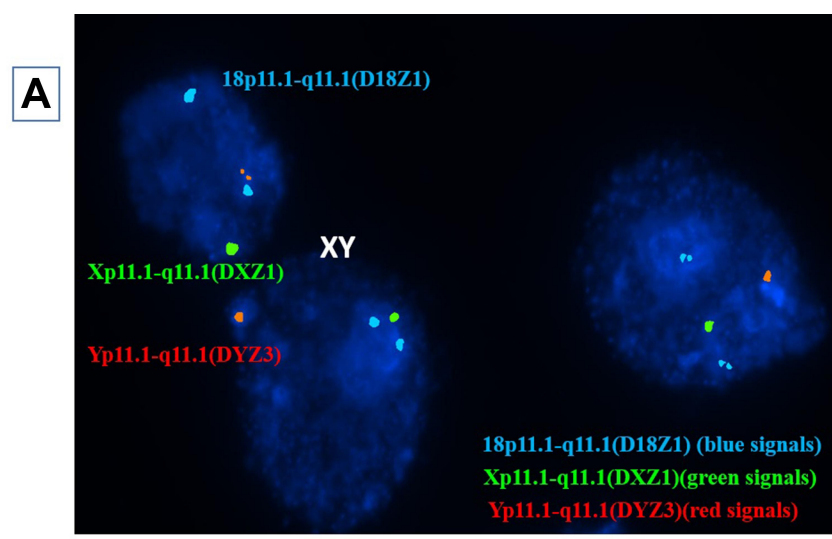

B

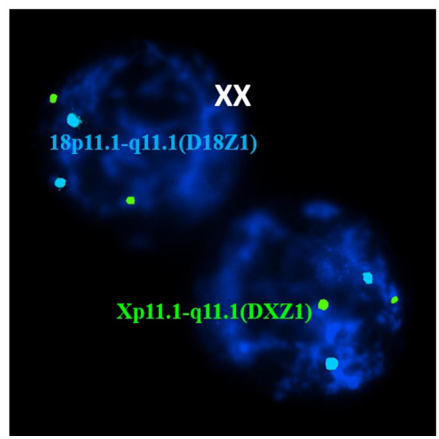

C

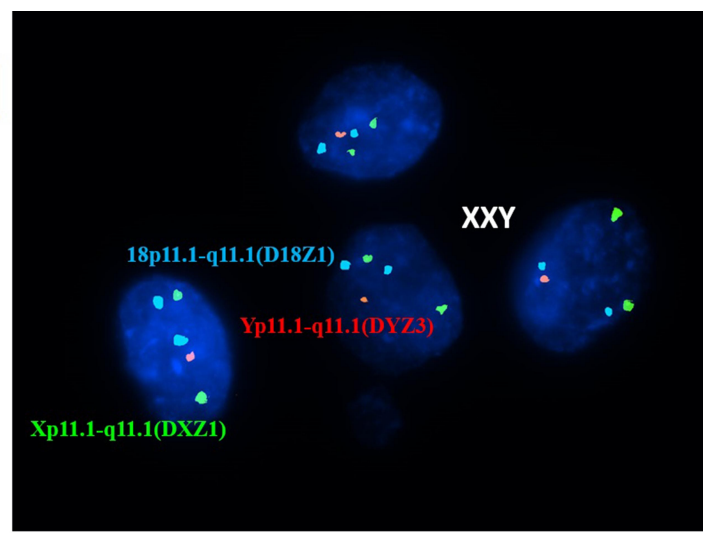

D

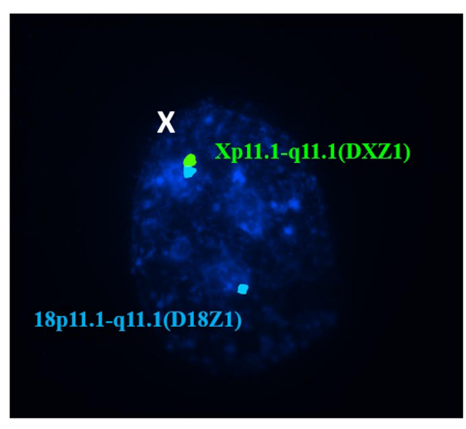

Figure I (A) Nuclei of three blastomeres using cytocell aquarius kit (REF: LPA 002) for probe combination; X chromosome centromere, XpII.I- qI I.I (DXZI) Green, Y chromosome centromere, YpI I.I-qII.I (DYZ3) Red and 18 chromosome centromere, I8pII.I- qII.I (DI8ZI) Blue, each showing a single green, a single red and two blue signals representing a normal male embryo. (B) Nuclei of two blastomeres each showing two green and two blue signals representing a normal female embryo. (C) Nuclei of four trophoblasts each with two blue signals, two green signals and one red signal representing an XXY embryo. (D) A nucleus of a blastomere showing two blue signals and a single green signal representing a Turner syndrome embryo (monosomy $\mathrm{X}$ ).

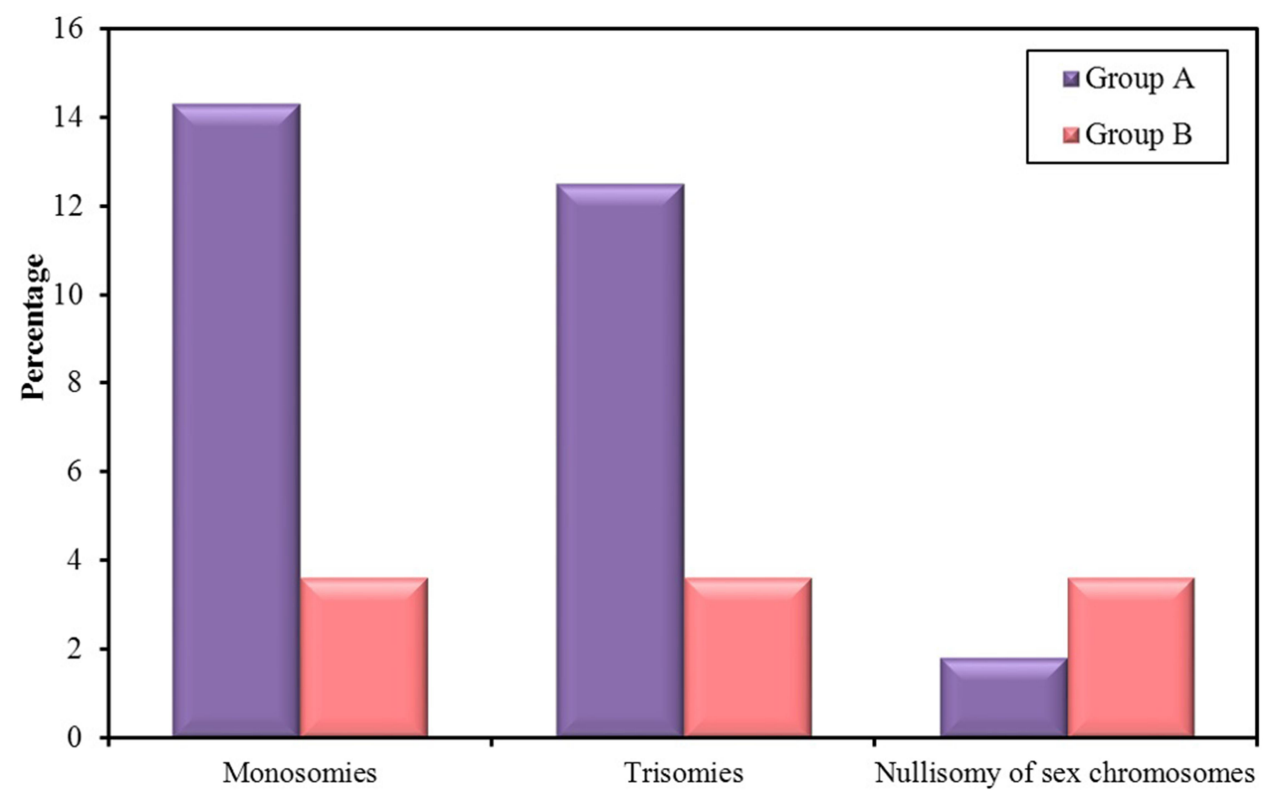

Figure 2 Frequencies of different types of aneuploidies detected in group A and B.

blastocyst biopsy multiple trophoblastic cells were retrieved for analysis. On classifying the total number of embryos analyzed (112 embryos) according to the day on which the embryo biopsy was retrieved, it was found that embryo biopsies were retrieved from 88 embryos (78.6\%) and from 24 embryos (21.4\%) on day 5 and day 3 , respectively. 


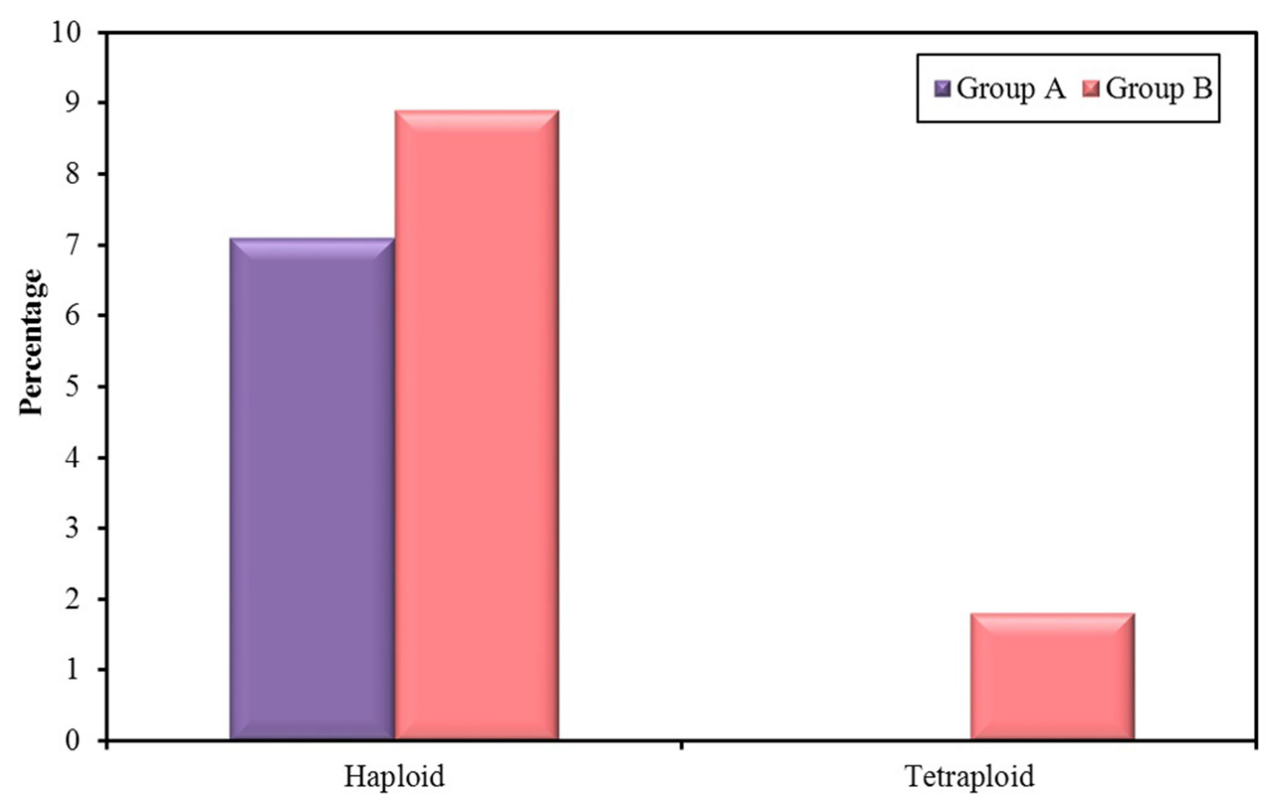

Figure 3 Frequencies of Ploidies detected in group A and B.

A

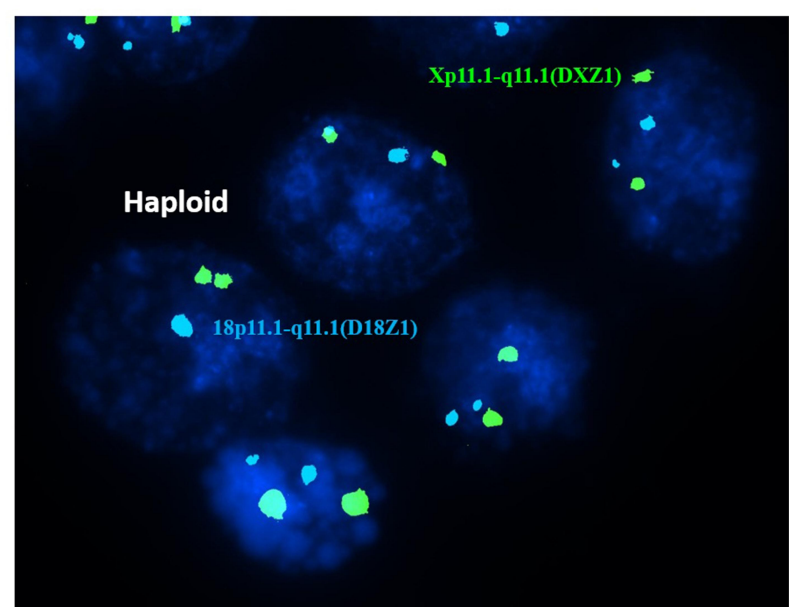

B

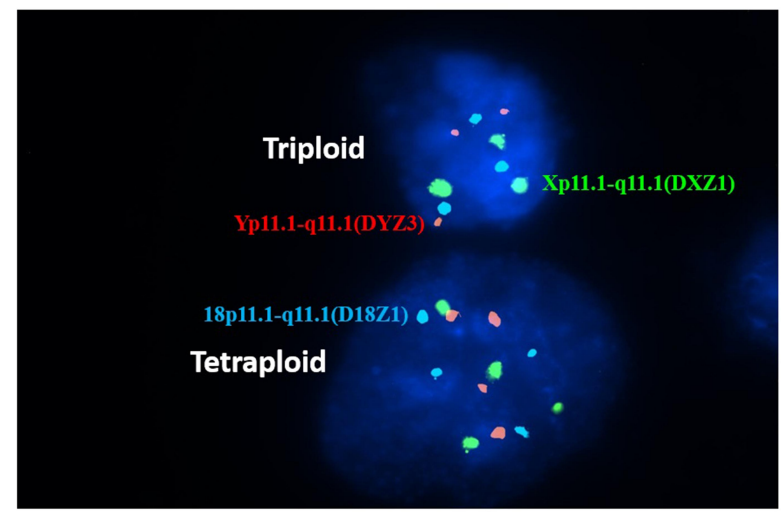

Figure 4 (A) Nuclei of multiple trophoblasts showing multiple diploid trophoblasts (two blue and two green signals) and a single haploid trophoblast (a single blue and green signal) representing a mosaic diploid-haploid embryo. (B) Nuclei of two trophoblasts showing a tetraploid trophoblast (four red, four green and four blue signals) and a triploid trophoblast (three red, three green and three blue signals).

Out of the 22 cases included in group A, biopsies of only two couples were retrieved on day $3(9.1 \%)$, while the biopsies of the remaining 20 couples were retrieved on day $5(90.9 \%)$. In group B, biopsies of only 8 couples were retrieved on day $3(40 \%)$, while the biopsies of the remaining 12 couples were retrieved on day 5 (60\%).

The frequencies of normal and abnormal embryos detected according to the day of biopsy in both groups were presented in Tables 9 and 10. These data revealed that the frequency of normal embryos was slightly higher in embryos whose biopsy was obtained on day 5 when compared with embryos whose biopsy was obtained on day $3(64.8 \%$ versus 62.5 , respectively) without statistically significant difference $(\mathrm{p}=837)$.

\section{Discussion}

The global rates of male infertility ranged from $2.5 \%$ to $12 \%$ and it was estimated that approximately 30 million men were infertile. $^{32}$ The advent of ICSI in conjunction with PGD has revolutionized the treatment of men with severely 


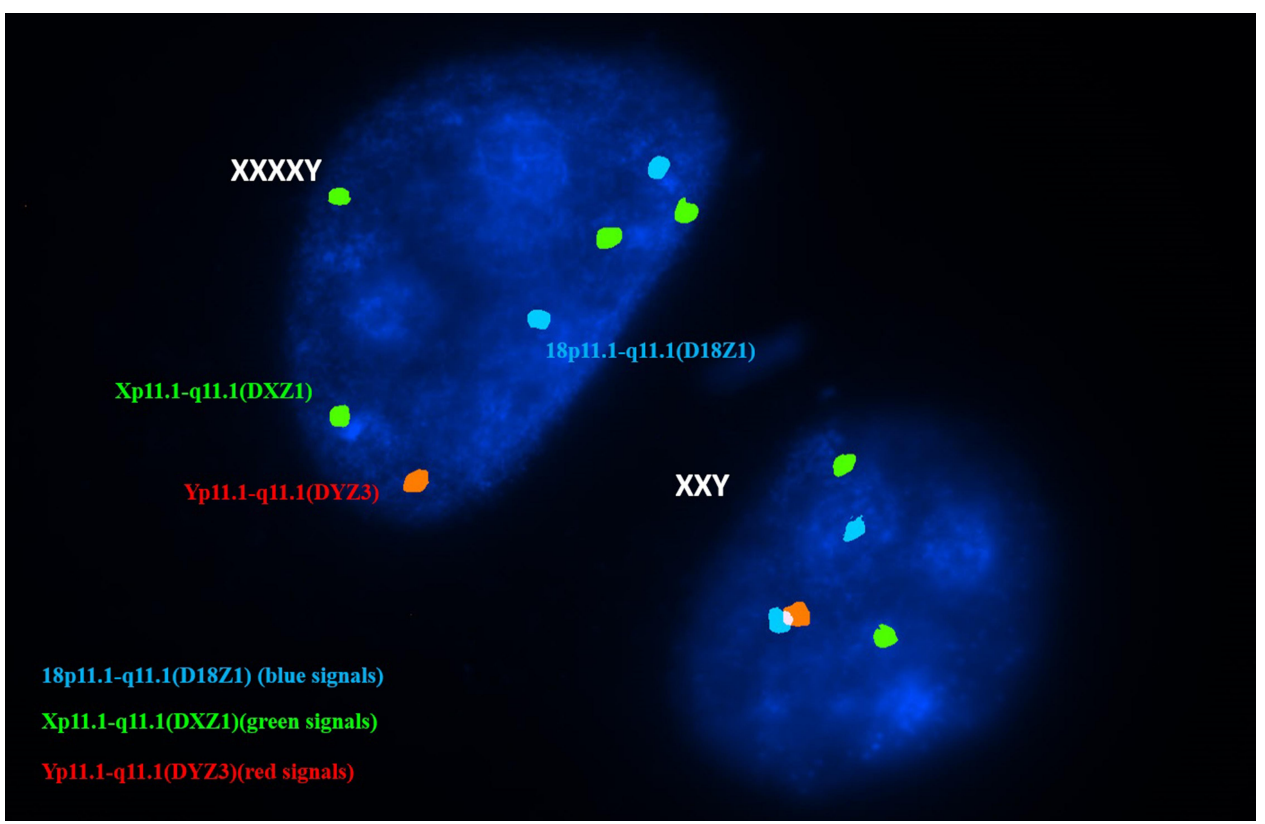

Figure 5 Nuclei of two blastomeres representing an aneuploid mosaic embryo with one cell showing $X X X X Y$ signal (two blue, four green and a single red signal) while the other showing XXY signal (two blue, two green and a single red signal).

compromised semen parameters and improved their chances of achieving normal term pregnancy. This is because ICSI greatly reduces the requirements for semen quality, motility and fertilization ability, while PGD enables the analysis of chromosomal complement of embryos of infertile men allowing the transfer of only chromosomally normal embryos, thus improving success rate and eliminating potential risks of using suboptimal sperms for fertilization. . $33,34^{2}$

The methodologies used to analyze human preimplantation embryos have revolutionized over the past two decades. Some of the first studies analyzing human preimplantation embryos used karyotype analysis, which although allows for analysis of all chromosomes, it requires dividing, metaphase-stage cells. This is a major drawback as only $24-36 \%$ of the embryos analyzed by karyotyping produces metaphases of sufficient quality for accurate chromosome analysis. Other disadvantages include that it is only capable of analyzing developing cells because arrested cells do not produce metaphases and cannot be analyzed and difficulty to identify individual chromosomes as it is hard to obtain optimal chromosomal banding and the possible loss of chromosomes during fixation of the nuclei. ${ }^{35}$

However, Karyotyping is no longer used for the analysis of chromosomal aneuploidies in human preimplantation embryos and the technique that is being used most often for the analysis of chromosomal aneuploidies in human preimplantation embryos is fluorescence in situ hybridization (FISH) ${ }^{36}$ FISH is usually favored because it gives information on the cytogenic status of each cell and it can be applied to single cells allowing analysis of chromosome number both in metaphase and interphase nuclei.

In the present study, we observed that lower sperm concentrations appear to be accompanied with higher rates of teratozoospermia. This goes in agreement with levron et al (2013), who documented that severe teratozoospermia is associated with lower sperm concentrations together with oligospermia. Lower sperm concentrations in patients with severe teratozoospermia were well documented by the results of analysis of different stages of gametogenesis which suggested that the pachytene I checkpoint produces meiotic arrest of abnormal cells which are more prevalent in patients with severe teratozoospermia leading to oligospermia or azoospermia. ${ }^{37}$ However, other meiotic studies have shown that a small number of pre-meiotic abnormal cells can escape the pachytene checkpoint, achieve meiosis and produce chromosomally abnormal spermatozoa whose percentage is directly proportional with the level of teratozoospermia. ${ }^{38,39}$

Failure rate of FISH procedure was lower in the biopsies retrieved on day 5 when compared with biopsies 
Table 6 Distribution of Potentially Viable Chromosomal Abnormalities Diagnosed in the Two Studied Groups

\begin{tabular}{|c|c|c|c|c|c|}
\hline \multirow[t]{2}{*}{ Abnormality } & \multicolumn{2}{|c|}{$\begin{array}{c}\text { Group } \\
A(n=56)\end{array}$} & \multicolumn{2}{|c|}{$\begin{array}{c}\text { Group } \\
B(n=56)\end{array}$} & \multirow[t]{2}{*}{$\mathrm{FE}_{\mathbf{p}}$} \\
\hline & No. & $\%$ & No. & $\%$ & \\
\hline Total number & 22 & 39.3 & 6 & 10.7 & $<0.001 *$ \\
\hline Sex chromosomal aneuploidies & 15 & 26.8 & 3 & 5.4 & $0.002^{*}$ \\
\hline$X X Y$ & 5 & 8.9 & 0 & 0.0 & 0.057 \\
\hline$X Y Y$ & I & 1.8 & 1 & 1.8 & 1.000 \\
\hline$x X X$ & I & 3.6 & 0 & 0.0 & 0.495 \\
\hline Monosomy X (turner syndrome) & 8 & 14.3 & 2 & 3.6 & $0.047^{*}$ \\
\hline Complex mosaic abnormalities & 7 & 12.5 & 2 & 3.6 & 0.162 \\
\hline Total mosaic abnormalities & 2 & 3.6 & 0 & 0.0 & 0.495 \\
\hline Mosaic $(X X Y$ and $X X X X Y)$ & I & 1.8 & 0 & 0.0 & 1.000 \\
\hline Mosaic (haploid and Turner syndrome) & I & 1.8 & 0 & 0.0 & 1.000 \\
\hline Diploid mosaic abnormalities & 5 & 8.9 & 2 & 3.6 & 0.438 \\
\hline Diploid-aneuploid mosaics & 3 & 5.4 & 0 & 0.0 & 0.243 \\
\hline Mosaic (normal and turner syndrome) & 2 & 3.6 & 0 & 0.0 & 0.495 \\
\hline Mosaic (normal and trisomy 18 ) & I & 1.8 & 0 & 0.0 & 1.000 \\
\hline Diploid-haploid mosaics & 0 & 0.0 & 2 & 3.6 & 0.495 \\
\hline Mosaic (normal and haploid) & 0 & 0.0 & 2 & 3.6 & 0.495 \\
\hline \multicolumn{6}{|l|}{ Diploid-polyploid mosaics } \\
\hline Mosaic (normal and tetraploid) & I & 1.8 & 0 & 0.0 & 1.000 \\
\hline \multicolumn{6}{|l|}{ Diploid-polyploid-aneuploid mosaics } \\
\hline Mosaic; normal, tetraploid-aneuploid (72,XXXYYY), triploid-aneuploid (100,XXXXYYYY) & I & 1.8 & 0 & 0.0 & 1.000 \\
\hline Autosomal aneuploidies & 0 & 0.0 & I & 1.8 & 1.000 \\
\hline Trisomy 18 & 0 & 0.0 & I & 1.8 & 1.000 \\
\hline
\end{tabular}

Notes: ${ }^{\mathrm{FE}} \mathrm{p}, \mathrm{P}$ value for Fisher Exact for Chi-square test for comparing between the two groups. *Statistically significant at $\mathrm{p} \leq 0.05$.

retrieved on day 3 in both groups (21.5\% versus $28.6 \%$ in group A and $19.6 \%$ versus $29.6 \%$ in group B) although the difference was not statistically significant $(p=0.647$ and $\mathrm{p}=0.326$, respectively) which matches with the recommendations of Cimadomo et al, 2016; $;^{40}$ Dahdouh et al, $2015^{41}$ and Scott et al, $2013^{42}$ that the blastocyst stage is the optimal time to perform biopsies for preimplantation genetic testing in order to avoid many of the pitfalls and limitations of cleavage stage biopsy and FISH analysis.

Trophectoderm biopsy allows the aspiration of multiple cells for analysis and thus reduces the possibility of failure due to loss of nuclear materials, inadequate hybridization, probe insufficiency, damaged or incomplete nuclei, nuclei covered with debris or nuclei without clear signals. Clearly, it provides sufficient material for an effective and more reliable diagnosis of embryos compared to blastomere biopsy on day 3. Moreover, it does not seem to compromise embryo implantation and pregnancy rates in PGD cycles. ${ }^{40-43}$
Lower frequencies were reported by Kahraman et al, $2003^{44}$ and $2006^{45}$ who detected a failure rate of $15 \%$ and $8.4 \%$, respectively, of biopsies aspirated on day 3 . This

Table 7 Distribution of Potentially Non-Viable Chromosomal Abnormalities Diagnosed in the Two Studied Groups

\begin{tabular}{|l|c|c|c|c|c|}
\hline \multirow{2}{*}{ Abnormality } & \multicolumn{2}{|c|}{$\begin{array}{c}\text { Group } \\
\text { A (n=56) }\end{array}$} & \multicolumn{2}{c|}{$\begin{array}{c}\text { Group } \\
\text { B (n=56) }\end{array}$} & \multirow{2}{*}{ FE } \\
\cline { 2 - 5 } & No. & $\%$ & No. & $\%$ & \\
\hline Total number & 5 & 8.9 & 8 & 14.3 & 0.376 \\
\hline Haploid & 4 & 7.1 & 5 & 8.9 & 1.000 \\
\hline Tetraploid & 0 & 0.0 & 1 & 1.8 & 1.000 \\
\hline $\begin{array}{l}\text { Nullisomy of sex } \\
\text { chromosomes }\end{array}$ & 1 & 1.8 & 2 & 3.6 & 1.000 \\
\hline
\end{tabular}

Note: ${ }^{\mathrm{FE}} \mathrm{p}$, $\mathrm{P}$ value for Fisher Exact for Chi-square test for comparing between the two groups. 
Table 8 Distribution of Percentages of Normal and Abnormal Cells in Mosaic Embryos Diagnosed in the Two Studied Groups

\begin{tabular}{|c|c|c|c|c|c|c|c|}
\hline Day of Biopsy & $\begin{array}{c}\text { Patient } \\
\text { No. }\end{array}$ & Grp. & Result & $\begin{array}{l}\text { Type of } \\
\text { Mosaicism }\end{array}$ & $\begin{array}{c}\text { No. of } \\
\text { Analyzed Cells }\end{array}$ & $\begin{array}{c}\text { No. of } \\
\text { Abnormal Cells }\end{array}$ & $\begin{array}{c}\text { No. of } \\
\text { Normal Cells }\end{array}$ \\
\hline \multirow[t]{8}{*}{$\begin{array}{l}\text { Day } 5 \text { mosaic } \\
\text { embryos }\end{array}$} & 6 & A & Mosaic $(X X X X Y, X X Y)$ & $\begin{array}{l}\text { Aneuploid } \\
\text { mosaic }\end{array}$ & 2 & $2(100 \%)$ & 0 \\
\hline & 7 & A & $\begin{array}{l}\text { Mosaic (normal, trisomy } \\
\text { ।8) }\end{array}$ & $\begin{array}{c}\text { Diploid } \\
\text { aneuploid mosaic }\end{array}$ & 2 & I (50\%) & I (50\%) \\
\hline & 8 & A & $\begin{array}{l}\text { Mosaic (normal, } \\
\text { tetraploid) }\end{array}$ & $\begin{array}{l}\text { Diploid-polyploid } \\
\text { mosaic }\end{array}$ & 6 & I (I7\%) & $5(83 \%)$ \\
\hline & 9 & A & $\begin{array}{c}\text { Mosaic (normal, triploid, } \\
\text { tetraploid) }\end{array}$ & $\begin{array}{l}\text { Diploid-polyploid } \\
\text { mosaic }\end{array}$ & 7 & $2(28.6 \%)$ & 5 (7I.4\%) \\
\hline & 15 & A & Mosaic (haploid, turner) & $\begin{array}{l}\text { Aneuploid } \\
\text { mosaic }\end{array}$ & 2 & $2(100 \%)$ & 0 \\
\hline & 20 & A & Mosaic (normal, turner) & $\begin{array}{l}\text { Diploid } \\
\text { aneuploid mosaic }\end{array}$ & 4 & I (25\%) & $3(75 \%)$ \\
\hline & 21 & A & Mosaic (normal, turner) & $\begin{array}{c}\text { Diploid } \\
\text { aneuploid mosaic }\end{array}$ & 3 & I (33.3\%) & $2(66.7 \%)$ \\
\hline & 41 & B & Mosaic (normal, haploid) & $\begin{array}{l}\text { Diploid-haploid } \\
\text { mosaic }\end{array}$ & 3 & I (33.3\%) & $2(66.7 \%)$ \\
\hline $\begin{array}{l}\text { Total } \\
\text { D3 mosaic } \\
\text { embryos } \\
\text { Total }\end{array}$ & 26 & B & Mosaic (normal, haploid) & $\begin{array}{l}\text { Diploid-haploid } \\
\text { mosaic }\end{array}$ & $\begin{array}{c}29 \\
3 \\
3\end{array}$ & $\begin{array}{c}\text { II (37.9\%) } \\
\text { I } \\
\text { I (33.3\%) }\end{array}$ & $\begin{array}{c}18(62.1 \%) \\
2 \\
2(66.7 \%)\end{array}$ \\
\hline
\end{tabular}

lower rate could be due to setting a different melting temperature (73C instead of $74 \mathrm{C}$ in the current study).

We determined that frequencies of chromosomally abnormal embryos were almost doubled in patients with severe teratozoospermia (48.2\%) when compared to patients with moderate teratozoospermia (25\%). Barely distinguishable result has been recently reported by Somova et al (2017) who detected chromosomal abnormalities in $43.75 \%$ of analyzed embryos from men with severe teratozoospermia. ${ }^{46}$

These results were also consistent with the study of Mazzilli et al (2017) who reported chromosomal abnormalities in $28.3 \%$ of embryos of patients with moderate teratozoospermia. However, they reported a lower rate $(33 \%)$ of chromosomal abnormalities in embryos of men with severe teratozoospermia which could be due to application of PCR analysis of blastocysts only, as sperm derived abnormalities may result in early interruption of embryo development leading to arrest of chromosomally abnormal embryos in cleavage stage. $^{47}$
In the current study, we determined that severe teratozoospermia appears to be a significant risk factor for increased sex chromosomal aneuploidy. Strikingly, aneuploidy rate almost tripled in group A embryos (28.6\%) when compared to aneuploidy rate in group B embryos $(10.7 \%)(p=0.017)$. These results provide further support to Kiseleva et al (2017) who reported a doubled aneuploidy rate in embryos of patients with severe teratozoospermia versus moderate teratozoospermia although lower rates were reported $(8.4 \%$ versus $4.3 \%)$ owing to the use of morphologically selected spermatozoa by higher magnification (IMSI) and due to assessing DNA fragmentation levels in semen samples and including only those with levels less than $15 \%$ in the study. ${ }^{48}$ These findings also substantiate previous results of Rodriguez-Purata et al (2016) and García-Ferreyra et al (2015) who reported a higher rate of aneuploidy in embryos of severely teratozoospermic men in comparison with moderately teratozoospermic ones although the increase did not reach significant levels which could be attributed to higher maternal and paternal ages than those included in the 
Table 9 Distribution of Normal and Abnormal Embryos Detected in Couples Whose Biopsy Was Retrieved on Day 5

\begin{tabular}{|c|c|c|c|c|}
\hline Group & No. & $\begin{array}{c}\text { No. of } \\
\text { Embryos } \\
\text { Analyzed }\end{array}$ & $\begin{array}{c}\text { No. of } \\
\text { Abnormal } \\
\text { Embryos }\end{array}$ & $\begin{array}{c}\text { No. of } \\
\text { Normal } \\
\text { Embryos }\end{array}$ \\
\hline \multirow[t]{20}{*}{ A } & 3 & 3 & 1 & 2 \\
\hline & 4 & 1 & 1 & 0 \\
\hline & 5 & 3 & 1 & 2 \\
\hline & 6 & 2 & 1 & I \\
\hline & 7 & 3 & 1 & 2 \\
\hline & 8 & 3 & I & 2 \\
\hline & 9 & 3 & 1 & 2 \\
\hline & 10 & 2 & 1 & 1 \\
\hline & 11 & 2 & 1 & I \\
\hline & 12 & I & 1 & 0 \\
\hline & 13 & 2 & I & I \\
\hline & 14 & I & 1 & 0 \\
\hline & 15 & 3 & 2 & I \\
\hline & 16 & 3 & I & 2 \\
\hline & 17 & I & 0 & 1 \\
\hline & 18 & 2 & 1 & I \\
\hline & 19 & 2 & 1 & I \\
\hline & 20 & 6 & 3 & 3 \\
\hline & 21 & 3 & 1 & 2 \\
\hline & 22 & 5 & 2 & 3 \\
\hline \multirow[t]{12}{*}{ B } & 31 & 2 & 0 & 2 \\
\hline & 32 & 1 & 0 & 1 \\
\hline & 33 & 3 & I & 2 \\
\hline & 34 & 2 & 1 & I \\
\hline & 35 & 2 & 0 & 2 \\
\hline & 36 & 6 & 1 & 5 \\
\hline & 37 & 1 & 1 & 0 \\
\hline & 38 & 2 & 0 & 2 \\
\hline & 39 & 6 & 1 & 5 \\
\hline & 40 & 3 & 2 & 1 \\
\hline & 41 & 5 & 1 & 4 \\
\hline & 42 & 4 & 0 & 4 \\
\hline Total No. & 32 & 88 & 31 & 57 \\
\hline Percentage & $76.2 \%$ & $78.6 \%$ & $35.2 \%$ & $64.8 \%$ \\
\hline
\end{tabular}

Table 10 Distribution of Normal and Abnormal Embryos Detected in Couples Whose Biopsy Was Retrieved on Day 3

\begin{tabular}{|l|c|c|c|c|}
\hline Group & $\begin{array}{c}\text { Patient } \\
\text { No. }\end{array}$ & $\begin{array}{c}\text { No. of } \\
\text { Embryos } \\
\text { Analyzed }\end{array}$ & $\begin{array}{c}\text { No. of } \\
\text { Abnormal } \\
\text { Embryos }\end{array}$ & $\begin{array}{c}\text { No. of } \\
\text { Normal } \\
\text { Embryos }\end{array}$ \\
\hline \multirow{3}{*}{ A } & I & 2 & I & I \\
\cline { 2 - 5 } & 2 & 3 & 2 & I \\
\cline { 2 - 5 } & 23 & 3 & 0 & 3 \\
\cline { 2 - 5 } & 25 & 2 & 1 & 1 \\
\cline { 2 - 5 } & 26 & 2 & 1 & 1 \\
\cline { 2 - 5 } & 27 & 2 & 2 & 0 \\
\cline { 2 - 5 } & 28 & 0 & 0 & 0 \\
\cline { 2 - 5 } & 29 & 2 & 0 & 2 \\
\cline { 2 - 5 } & 30 & 6 & 1 & 5 \\
\hline Total No. & 10 & 24 & 9 & 15 \\
\hline Percentage & $23.8 \%$ & $21.4 \%$ & $37.5 \%$ & $62.5 \%$ \\
\hline
\end{tabular}

present study. ${ }^{49,50}$ These results also confirm earlier study by Levron et al (2013) who reported a high frequency of chromosomes $\mathrm{X}, \mathrm{Y}$ and 18 aneuploidies in sperm of patients with severe teratozoospermia. ${ }^{37}$

It has been hypothesized that different types of human embryonic abnormalities can have a meiotic or a mitotic origin. Meiotic abnormalities prior to fertilization are the most likely mechanism of aneuploidy which is universal to all cells of the embryo. This could occur due to nondisjunction of entire chromosomes during meiosis I or II or premature division of a chromosome into its two sister chromatids during meiosis I, followed by their random segregation. Mitotic abnormalities can arise due to nondisjunction, endo-reduplication or anaphase lag that occurs most often during the first three divisions after fertilization which are controlled by sperm centrioles. Hence, sperm integrity is clearly necessary for normal mitotic division and early embryo development. Mitotic errors could be explained by defects in embryo cleavage related to defective sperm centrosome or an abnormal number of male centrioles resulting in the formation of abnormal spindle, with an abnormal distribution of chromosomes among sister cells. ${ }^{51-53}$ Aneuploidies could occur by different mechanisms such as premature cell division, cell fusion and chromosome breakage. ${ }^{54}$ It has been demonstrated 
that trisomies and monosomies mostly have a meiotic origin, while nullisomies, mosaicism, haploidy and polyploidies mostly have a mitotic origin. ${ }^{55-57}$

Sex chromosomes are specifically liable to meiotic non-disjunction; which is believed to be the mechanism of sperm aneuploidy, due to their unique structures, which provide only a few sites of recombination. ${ }^{37}$ Normally, the abnormal cells that suffer from non-disjunction of sex chromosomes during meiosis I or II are subjected to a complete or partial meiotic arrest by the pachytene checkpoint mechanism. Occasionally mutations of one or more of the genes involved in these DNA repair mechanisms produce chromosomally abnormal cells that escape the pachytene checkpoint and result in spermatozoa with disomy of sex chromosomes. ${ }^{58}$

Haploid embryos were detected in 4 embryos (7.1\%) and in 5 embryos $(8.9 \%)$ in group A and group B, respectively, while tetraploidy was detected in only a single embryo in group B (1.8\%) and none of group A embryos. Similar percentages were reported by Zakharova et al, $2014^{59}$ who detected haploidy in approximately $7.5 \%$ of embryos in patients with moderate and severe teratozoospermia; however, a higher percentage of tetraploidy (approximately 6.4\%) was detected in both groups which could be attributed to larger sample size than the current study. On the contrary, the results of the present study are in disagreement with the study performed by Magli et al, $2009^{60}$ in which a male effect is evident with an increase in post-meiotic abnormalities such as haploid and polyploidy embryos that is proportional to the severity of the male factor condition. They detected ploidy abnormalities in $9 \%$ versus $14 \%$ of embryos of patients with moderate and severe teratozoospermia, respectively. This discrepancy could be due to the limited sample size in the present study in comparison to the 230 couples under analysis.

It has been demonstrated that ploidies originate predominantly during post-fertilization mitotic divisions owing to increased levels of sperm centrioles' defects teratozoospermic men. Moreover, haploid cells might originate from premature cell division without prior duplication, while tetraploid cells could originate by endoreplication of the chromosomes in a single two-cell embryo, cell fusion or cytokinesis failure. $^{54}$ Polyploid cells may also be a physiological phenomenon during preimplantation development. Other mechanisms of development of embryos with uniform polyploid blastomeres are polyandry (dispermic or trispermic fertilization) or less commonly by polygyny (monospermic fertilization with retention of the first polar body). FISH artefacts are unlikely because the polyploid chromosome patterns involve multiple chromosomes. ${ }^{61}$

In the present study, the total number of mosaic abnormalities detected was dramatically higher in group A embryos (12.5\%) than in group B embryos (3.6\%), however not statistically significantly different $(\mathrm{p}=$ 0.162 ). Moreover, both types of mosaicism were more prevalent in group A, as diploid mosaic type was detected in $7.1 \%$ and $3.6 \%$ of group $\mathrm{A}$ and group $\mathrm{B}$ embryos, respectively, while the total mosaic type was detected in group A embryos (5.4\%) and none of group B embryos; however, the difference was not statistically significant $(\mathrm{FEp}=0.679$ and $\mathrm{FEp}=0.243$, respectively $)$.

Our findings appear to be well substantiated by Magli et al, 2009, ${ }^{60}$ Simon et al, $2007^{62}$ and Silber et al, $2003^{51}$ who reported that post-meiotic abnormalities as mosaicism in early developmental stages are proportional to the severity of the male factor condition and that mosaicism rates increase as the degree of sperm characteristics decreased. However, higher rates were reported by Simon et al, 2007 who detected mosaicism in $15.1 \%$ and $20.8 \%$ of embryos of men with moderate and severe teratozoospermia, respectively. This higher incidence could be due to analysis of a wider panel of chromosomes $13,15,16,18,21,22, \mathrm{X}$ and $\mathrm{Y}$.

Mosaicism originates predominantly from mitotic errors in first few embryo divisions after fertilization due to abnormal number of male centrioles (haploid mosaics none, polyploidy mosaics two or more), or suboptimal centriole function which increase significantly in proportion to the level of teratozoospermia. In such case, the first mitotic spindle will not form properly leading to failure of cytokinesis, creating two chromosomally abnormal cells. ${ }^{51,52,55-57}$ Mitotic errors could also be due to reduced expression of certain cell cycle checkpoint genes during early embryonic development or less functional cell cycle checkpoint mechanisms that may lead to chromosomal segregation errors in the first cleavages of human preimplantation embryos and thus to mosaicism. ${ }^{53,63}$

Several other mechanisms have been proposed for the development of mosaic embryos with diploid or haploid cells, including cell fusion, nuclear division without previous chromosome duplication, incorporation of a polar body nucleus into a diploid embryo, incorporation of a second sperm (n) nucleus into a haploid embryo. ${ }^{64,65}$ 
In the current study, the total number of potentially viable chromosomal abnormalities was significantly higher in group A (39.3\%) when compared to group B (10.7\%) (p $<0.001)$. This is in agreement with Rodrigo et al, 2010 who reported a significant increase in the proportion of viable chromosomally abnormal embryos with the increase in sperm abnormalities owing to the dramatic increase in sex chromosomal aneuploidies (threefold to sixfold) in embryos of patients with teratospemria compared to normal population. ${ }^{19}$ Their findings concur well with our study in which viable sex chromosomes were significantly higher in group A $(26.8 \%)$ when compared to group $\mathrm{B}(5.4 \%)(\mathrm{p}=0.002)$.

Evidently, the higher occurrence of mosaic embryos which are potentially viable in group A provides another possible explanation, as in the present study, all diploid mosaic embryos had a percentage of abnormal cells less than $50 \%$ of the cells analyzed and were considered potentially viable as proposed by Fragouli et al, 2017 who documented that blastocysts that had $40-80 \%$ of the analyzed cells diagnosed as abnormal were associated with a pregnancy rate of $22 \%$ ongoing pregnancies, and those with $<40 \%$ abnormal cells resulted in a $56 \%$ ongoing pregnancy rate. ${ }^{31}$

This is further supported by the results of Munne et al, 2017 which suggested that the majority of embryos with $20-40 \%$ abnormal cells in their biopsy sample have euploid inner cell masses (ICMs) and could result in a viable normal pregnancy. This opinion has been reinforced by many previous studies which classified embryos with up to $50 \%$ abnormal cells as diploid and considered them viable. According to them a low percentage of aneuploid cells in an otherwise diploid embryo would be clinically irrelevant and are selected against during early development. They also suggested that an overly cautious approach to the transfer of mosaic embryos risks an undesired negative impact on cumulative pregnancy rates, because some embryos with the potential to produce babies may be discarded. They recommended that these embryos should not be placed in the same category as those that are fully aneuploid and should be considered as a third group of intermediate potential. ${ }^{66-74}$

In the present study, the frequency of normal embryos was slightly higher in embryos whose biopsy was obtained on day 5 when compared with embryos whose biopsy was obtained on day 3 (64.8\% versus 62.5 , respectively) without statistical significant difference $(\mathrm{p}=837)$. These results correlate with Beyer et al, 2017 who reported an increase in the percentage of normal embryos between D3 embryos (22.3\%) and D5 embryos (53.1\%). ${ }^{75}$ These results are also in agreement with Michal Dekel-Naftali et al 2013 who reported that while on 'Day 3' only $31 \%$ of the embryos were detected as normal, on 'Day $5-6$ ', 44\% of the embryos were classified as normal. ${ }^{76}$

These findings confirm the results of Fragouli et al, 2013 and McCoy et al, 2015 that documented a strong natural selection process against chromosomal abnormalities during early embryogenesis, occurring specifically between day 3 and day 5/6 of development and is presumably due to impaired viability. This process significantly increases the proportion of normal/balanced embryos and concomitantly decreases the proportion of aneuploid or unbalanced embryos and this is why blastocyst biopsy enhances the likelihood of identifying a normal/balanced embryo for transfer. ${ }^{77,78}$ Fragouli et al, 2013 have proposed that cell cycle regulatory mechanisms, which act to monitor and maintain accurate chromosome segregation, become active following the switch from the maternal genome to the embryonic genome at the blastomere stage, removing genetically unbalanced cells. ${ }^{77}$

Optimistically, these results give a hopeful encouragement for patients with absolute teratozoospermia and other patients with varying degrees of teratozoospermia and compel both clinicians and geneticists who are obliged to offer paternity to these patients. The couple should receive nondirective, objective genetic counseling regarding the potential reproductive risks for abnormal offspring and should be provided with the necessary information of possible reproductive options and genetic testing methodologies available to be able to take an informative decision on whether they wish for a normal conception and a future prenatal genetic testing bearing in mind the possible risk of miscarriage or they wish to proceed with assisted reproduction (ICSI/IVF) accompanied with prenatal genetic screening.

\section{Conclusion}

The results obtained in the current study add further evidence that cases with severe teratozoospermia undergoing ICSI treatment can display a higher rate of sex chromosome aneuploidies in their embryos than cases with moderate teratozoospermia. Proper and careful genetic counseling should be offered to patients with teratozoospermia with emphasis on the increased risk of sex chromosomal aneuploidy in their offsprings and the importance of PGD to avoid this potential risk. FISH 
analysis is a fast, reliable and relatively cheap method to assess the sex chromosomal abnormalities in preimplantation embryos. More studies with higher numbers of cases are needed to assess the real impact of teratozoospermia on levels of chromosomal abnormalities in ICSI embryos.

\section{Data Sharing Statement}

Data are available on request to the corresponding author.

\section{Ethics Approval}

The research was reviewed and approved by the Ethics Committee (IORG\#: IORG0008812), Medical Research Institute, Alexandria University.

\section{Consent}

Written informed consent to participate and publish was obtained from each couple who participated in the study.

\section{Funding}

There is no funding to report.

\section{Disclosure}

The authors report no conflicts of interest in this work.

\section{References}

1. Brahem S, Mehdi M, Elghezal H, et al. Detection of DNA fragmentation and meiotic segregation in human with isolated teratozoospermia. J Assist Reprod Genet. 2011;28(1):41-48. doi:10.1007/s10815-010-9482-8

2. Mehdi M, Gmidène A, Brahem S, et al. Aneuploidy rate in spermatozoa of selected men with severe teratozoospermia. Andrologia. 2012;44:139-143. doi:10.1111/j.1439-0272.2010.01152.x

3. Ammar O, Mehdi M, Muratori M. Teratozoospermia: its association with sperm DNA defects, apoptotic alterations, and oxidative stress. Andrology. 2020;8(5):1095-1106. doi:10.1111/andr.12778

4. Oumaima A, Tesnim A, Zohra H, et al. Investigation on the origin of sperm morphological defects: oxidative attacks, chromatin immaturity, and DNA fragmentation. Environ Sci Poll Res. 2018;25 (14):13775-13786. doi:10.1007/s11356-018-1417-4

5. Figueiredo H, Tavares A, Ferrás L, et al. Isolated teratozoospermia and in vitro fertilization. J Assist Reprod Genet. 1996;13(1):64-68. doi:10.1007/BF02068872

6. Lundin K, Söderlund B, Hamberger L. The relationship between sperm morphology and rates of fertilization, pregnancy and spontaneous abortion in an in-vitro fertilization/intracytoplasmic sperm injection programme. Human Reprod (Oxford England). 1997;12 (12):2676-2681.

7. Terriou P, Giorgetti C, Auquier P, et al. Teratozoospermia influences fertilization rate in vitro but not embryo quality. Human Reprod (Oxford, England). 1997;12(5):1069-1072. doi:10.1093/humrep/ 12.5.1069

8. Ombelet W, Fourie FL, Vandeput H, et al. Teratozoospermia and in-vitro fertilization: a randomized prospective study. Human Reproduction. 1994;9(8):1479-1484. doi:10.1093/oxfordjournals.humrep.a138734
9. Grow DR, Oehninger S, Seltman HJ, et al. Sperm morphology as diagnosed by strict criteria: probing the impact of teratozoospermia on fertilization rate and pregnancy outcome in a large in vitro fertilization population. Fertility and Sterility. 1994;62(3):559-567. doi:10.1016/S0015-0282(16)56946-5

10. Taşdemir I, Tasdemir M, Tavukcuoglu S, et al. Effect of abnormal sperm head morphology on the outcome of intracytoplasmic sperm injection in humans. Human Reproduction (Oxford, England). 1997;12(6):1214-1217. doi:10.1093/humrep/12.6.1214

11. Sun F, Ko E, Martin RH. Is there a relationship between sperm chromosome abnormalities and sperm morphology? Reproductive Biology and Endocrinology. 2006;4(1):1-5. doi:10.1186/1477-78274-1

12. Calogero AE, et al. Aneuploidy rate in spermatozoa of selected men with abnormal semen parameters. Human Reproduction. 2001;16 (6):1172-1179. doi:10.1093/humrep/16.6.1172

13. Härkönen K, Suominen J, Lähdetie J. Aneuploidy in spermatozoa of infertile men with teratozoospermia. Int $J$ Androl. 2001;24 (4):197-205. doi:10.1046/j.1365-2605.2001.00280.x

14. Van Opstal D, Los FJ, Ramlakhan S, et al. Determination of the parent of origin in nine cases of prenatally detected chromosome aberrations found after intracytoplasmic sperm injection. Human Reprod. 1997;12(4):682-686. doi:10.1093/humrep/12.4.682

15. Bartels I, Schlosser M, Bartz UG, et al. Paternal origin of trisomy 21 following intracytoplasmic sperm injection (ICSI). Human Reprod. 1998;13(12):3345-3346. doi:10.1093/humrep/13.12.3345

16. Bonduelle M, Aytoz A, Van Assche E, et al. Incidence of chromosomal aberrations in children born after assisted reproduction through intracytoplasmic sperm injection. Human Reprod. 1998;13 (4):781-782. doi:10.1093/humrep/13.4.781

17. Ramasamy R, Scovell JM, Kovac JR, et al. Fluorescence in situ hybridization detects increased sperm aneuploidy in men with recurrent pregnancy loss. Fertility and Sterility. 2015;103(4):906-909. doi:10.1016/j.fertnstert.2015.01.029

18. Moretti E, Collodel G. Fluorescence in situ hybridization studies of sperm aneuploidies in infertile men. Open Androl J. 2009;1(1):1. doi:10.2174/1876827X00901010020

19. Rodrigo L, Peinado V, Mateu E, et al. Impact of different patterns of sperm chromosomal abnormalities on the chromosomal constitution of preimplantation embryos. Fertil Steril. 2010;94(4):1380-1386. doi:10.1016/j.fertnstert.2009.05.061

20. Robertson JA. Extending preimplantation genetic diagnosis: the ethical debate: ethical issues in new uses of preimplantation genetic diagnosis. Hum Reprod. 2003;18(3):465-471. doi:10.1093/humrep/de g100

21. Soini S, Ibarreta D, Anastasiadou V, et al. The interface between assisted reproductive technologies and genetics: technical, social, ethical and legal issues. Eur J Hum Genet. 2006;14(5):588-645. doi:10.1038/sj.ejhg. 5201598

22. Smith SE, Toledo AA, Massey JB, et al. Simultaneous detection of chromosomes X, Y, 13, 18, and 21 by fluorescence in situ hybridization in blastomeres obtained from preimplantation embryos. J Assist Reprod Genet. 1998;15(5):314-319. doi:10.1023/ A:1022504829854

23. Check J, Adelson HG, Schubert BR, et al. Evaluation of sperm morphology using Kruger's strict criteria. Arch Androl. 1992;28 (1):15-17. doi:10.3109/01485019208987674

24. Kahraman S, et al. Preliminary FISH studies on spermatozoa and embryos in patients with variable degrees of teratozoospermia and a history of poor prognosis. 2006;12(6):752-761.

25. Kiseleva Y, Abubakirov AJF. Teratozoospermia is Associated with the Embryo Aneuploidy and Leads to the Sex Ratio Imbalance. Sterility. 2017;108(3):e127.

26. Killeen PR. An alternative to null-hypothesis significance tests. Psychological Science. 2005;16(5):345-353. doi:10.1111/j.09567976.2005.01538.x 
27. Daniel WW. Biostatistics:A foundation for analysis in the health sciences. 5th edition. New York, Chichester, Brisbane, Toronto, Singapore: John Wiley \& Sons; 1991:209-215.

28. Pannucci CJ, Wilkins EG. Identifying and avoiding bias in research. Plastic Reconstruct Surg. 2010;126(2):619. doi:10.1097/ PRS.0b013e3181de24bc

29. Menkveld R, Holleboom CA, Rhemrev JP. Measurement and significance of sperm morphology. Asian J Androl. 2011;13(1):59. doi:10.1038/ aja. 2010.67

30. Charan J, Biswas T. How to calculate sample size for different study designs in medical research? Indian J Psychol Med. 2013;35(2):121. doi:10.4103/0253-7176.116232

31. Fragouli E, Alfarawati S, Spath K, et al. Analysis of implantation and ongoing pregnancy rates following the transfer of mosaic diploid-aneuploid blastocysts. Hum Genet. 2017;136(7):805-819. doi:10.1007/s00439-017-1797-4

32. Agarwal A, Mulgund A, Hamada A, et al. A unique view on male infertility around the globe. Reprod Biol Endocrinol. 2015;13(1):37. doi:10.1186/s12958-015-0032-1

33. García-Ferreyra J, et al. High aneuploidy rates observed in embryos derived from donated oocytes are related to male aging and high percentages of sperm DNA fragmentation. Clin Med Insights. 2015;9: S32769.

34. Hann MC, Lau PE, Tempest HG. Meiotic recombination and male infertility: from basic science to clinical reality? Asian J Androl. 2011;13(2):212. doi:10.1038/aja.2011.1

35. Clouston HJ, Fenwick J, Webb AL, et al. Detection of mosaic and non-mosaic chromosome abnormalities in 6- to 8-day old human blastocysts. Hum Genet. 1997;101(1):30-36. doi:10.1007/ s004390050581

36. Munne S, Fragouli E, Colls P, et al. Improved detection of aneuploid blastocysts using a new 12-chromosome FISH test. Reprod Biomed Online. 2010;20(1):92-97. doi:10.1016/j.rbmo.2009.10.015

37. Levron J, Aviram-Goldring A, Rienstien S, et al. Aneuploidy rates for chromosomes $\mathrm{X} / \mathrm{Y}$ and 18 among preselected spermatozoa in men with severe teratospermia. Reprod Biomed Online. 2013;27 (3):280-285. doi:10.1016/j.rbmo.2013.05.017

38. Egozcue S, et al. Human male infertility: chromosome anomalies, meiotic disorders, abnormal spermatozoa and recurrent abortion. Hum Reprod Update. 2000;6(1):93-105. doi:10.1093/humupd/6.1.93

39. Shi Q, Martin RH. Aneuploidy in human spermatozoa: FISH analysis in men with constitutional chromosomal abnormalities, and in infertile men. Reproduction. 2001;121(5):655-666. doi:10.1530/ rep. 0.1210655

40. Cimadomo D, Capalbo A, Ubaldi FM, et al. The impact of biopsy on human embryo developmental potential during preimplantation genetic diagnosis. BioMed Res Int. 2016;2016:2016. doi:10.1155/ 2016/7193075

41. Dahdouh EM, Balayla J, Audibert F, et al. Technical update: preimplantation genetic diagnosis and screening. J Obstetrics Gynaecol Canada. 2015;37(5):451-463. doi:10.1016/S1701-2163(15)30261-9

42. Scott KL, Hong KH, Scott RT. Jr, Selecting the optimal time to perform biopsy for preimplantation genetic testing. Fertility Sterility. 2013;100(3):608-614. doi:10.1016/j.fertnstert.2013.07.004

43. Mastenbroek S, Twisk M, van Echten-arends J, et al. In vitro fertilization with preimplantation genetic screening. $N$ Engl J Med. 2007;357(1):9-17. doi:10.1056/NEJMoa067744

44. Kahraman S, Findikli N, Berkil H, et al. Results of preimplantation genetic diagnosis in patients with Klinefelter's syndrome. Reprod BioMed Online. 2003;7(3):346-352. doi:10.1016/S1472-6483(10) 61876-7

45. Kahraman S, Findikli N, Biricik A, et al. Preliminary FISH studies on spermatozoa and embryos in patients with variable degrees of teratozoospermia and a history of poor prognosis. Reprod Biomed Online. 2006;12(6):752-761. doi:10.1016/S1472-6483(10)61087-5
46. Somova $\mathrm{O}$, et al. The choice of the best embryo originating from spermatozoa of men with severe male factor infertility: morphokinetics and Next-Generation Sequencing (NGS) results. In Human reproduction. Oxford, England: Oxford Univ Press; 2017.

47. Mazzilli R, Cimadomo D, Vaiarelli A, et al. Effect of the male factor on the clinical outcome of intracytoplasmic sperm injection combined with preimplantation aneuploidy testing: observational longitudinal cohort study of 1,219 consecutive cycles. Fertil Steril. 2017;108 (6):961-972. doi:10.1016/j.fertnstert.2017.08.033

48. Kiseleva YY, Azova MM, Kodyleva TA, et al. The increase in aneuploidy of embryos Is associated with pathological morphology of the sperm. Russian $J$ Genetics. 2017;53(12):1378-1381. doi:10.1134/S1022795417120055

49. Rodriguez-Purata J, Sekhon L, Lee JA, et al. Does severe teratozoospermia is correlated with embryonic aneuploidy rates? Fertil Steril. fertnstert.2016.07.659

50. Garcia-Ferreyra J, Luna D, Villegas L, et al. High aneuploidy rates observed in embryos derived from donated oocytes are related to male aging and high percentages of sperm DNA fragmentation. Clin Med Insights. 2015;9:21-27. doi:10.4137/CMRH.S32769

51. Silber S, Escudero T, Lenahan K, et al. Chromosomal abnormalities in embryos derived from testicular sperm extraction. Fertil Steril. 2003;79(1):30-38. doi:10.1016/S0015-0282(02)04407-2

52. Chatzimeletiou K, Morrison EE, Prapas N, et al. The centrosome and early embryogenesis: clinical insights. Reprod Biomed Online. 2008;16(4):485-491. doi:10.1016/S1472-6483(10)60455-5

53. King RW. When $2+2=5$ : the origins and fates of aneuploid and tetraploid cells. Biochim Biophys Acta. 2008;1786(1):4-14. doi:10.1016/j.bbcan.2008.07.007

54. Mantikou E, Wong KM, Repping S, et al. Molecular origin of mitotic aneuploidies in preimplantation embryos. Biochim Biophys Acta. 2012;1822(12):1921-1930. doi:10.1016/j.bbadis.2012.06.013

55. Mantzouratou A, Mania A, Fragouli E, et al. Variable aneuploidy mechanisms in embryos from couples with poor reproductive histories undergoing preimplantation genetic screening. Hum Reprod. 2007;22(7):1844-1853. doi:10.1093/humrep/dem102

56. Mertzanidou A, Wilton L, Cheng J, et al. Microarray analysis reveals abnormal chromosomal complements in over $70 \%$ of 14 normally developing human embryos. Hum Reprod. 2013;28(1):256-264. doi:10.1093/humrep/des362

57. Fragouli E, Wells D. Human Embryonic Aneuploidy. Chichester:: John Wiley \& Sons Ltd; 2014.

58. Wong EC, Ferguson KA, Chow V, et al. Sperm aneuploidy and meiotic sex chromosome configurations in an infertile XYY male. Hum Reprod. 2008;23(2):374-378. doi:10.1093/humrep/de $\mathrm{m} 377$

59. Zakharova EE, Zaletova VV, Krivokharchenko AS. Biopsy of human morula-stage embryos: outcome of 215 IVF/ICSI cycles with PGS. PLoS One. 2014;9(9):e106433. doi:10.1371/journal.pone.010 6433

60. Magli M, Gianaroli L, Ferraretti AP, et al. Paternal contribution to aneuploidy in preimplantation embryos. Reprod Biomed Online. 2009;18(4):536-542. doi:10.1016/S1472-6483(10)60131-9

61. Ruangvutilert P, Delhanty JDA, Serhal P, et al. FISH analysis on day 5 post-insemination of human arrested and blastocyst stage embryos. Prenat Diagn. 2000;20(7):552-560. doi:10.1002/1097-0223(200007) 20:7<552::AID-PD871>3.0.CO;2-F

62. Delgado A, De los Santos M, Buendia P, et al. Increased incidence of mosaic embryos with the microinjection of spermatozoa with abnormal morphology. Fertil Steril. 2007;88:S229-S230. doi:10.1016/j. fertnstert.2007.07.785

63. Delhanty JD. Mechanisms of aneuploidy induction in human oogenesis and early embryogenesis. Cytogenetic and Genome Research. 2005;111(3-4):237-244. doi:10.1159/000086894 
64. Munne S, Grifo J, Cohen J, et al. Chromosome abnormalities in human arrested preimplantation embryos: a multiple-probe FISH study.. Am J Hum Genet. 1994;55(1):150-159.

65. Benkhalifa M, Janny L, Vye P, et al. Assessment of polyploidy in human morulae and blastocysts using co-culture and fluorescent in-situ hybridization. Hum Reprod. 1993;8(6):895-902. doi:10.1093/ oxfordjournals.humrep.a138162

66. Munne S, Alikani M, Ribustello L, et al. Euploidy rates in donor egg cycles significantly differ between fertility centers. Hum Reprod. 2017;32(4):743-749. doi:10.1093/humrep/dex031

67. Van Echten-arends J, Mastenbroek S, Sikkema-Raddatz B, et al. Chromosomal mosaicism in human preimplantation embryos: a systematic review. Hum Reprod Update. 2011;17(5):620-627. doi:10.1093/humupd/dmr014

68. Baart EB, Martini E, van den Berg I, et al. Preimplantation genetic screening reveals a high incidence of aneuploidy and mosaicism in embryos from young women undergoing IVF. Hum Reprod. 2006;21 (1):223-233. doi:10.1093/humrep/dei291

69. Bielanska M, Tan SL, Ao A. Chromosomal mosaicism throughout human preimplantation development in vitro: incidence, type, and relevance to embryo outcome. Hum Reprod. 2002;17(2):413-419. doi:10.1093/humrep/17.2.413

70. Munne S, Grifo J, Wells D. Mosaicism: "survival of the fittest" versus "no embryo left behind". Fertil Steril. 2016;105(5):1146-1149. doi:10.1016/j.fertnstert.2016.01.016

71. Edgar DH, Archer J, McBain J, et al. Embryonic factors affecting outcome from single cryopreserved embryo transfer. Reprod Biomed Online. 2007;14(6):718-723. doi:10.1016/S1472-6483(10)60674-8

72. Eggan K, Rode A, Jentsch I, et al. Male and female mice derived from the same embryonic stem cell clone by tetraploid embryo complementation. Nat Biotechnol. 2002;20(5):455-459. doi:10.1038/nbt0502-455
73. Vanneste E, Voet T, Melotte C, et al. What next for preimplantation genetic screening? High mitotic chromosome instability rate provides the biological basis for the low success rate. Hum Reprod. 2009;24 (11):2679-2682. doi:10.1093/humrep/dep266

74. Ziebe S, et al. FISH analysis for chromosomes 13, 16, 18, 21, 22, $\mathrm{X}$ and $\mathrm{Y}$ in all blastomeres of IVF pre-embryos from 144 randomly selected donated human oocytes and impact on pre-embryo morphology. Hum Reprod. 2003;18(12):2575-2581. doi:10.1093/ humrep/deg489

75. Beyer CE, Willats E. Natural selection between day 3 and day $5 / 6$ PGD embryos in couples with reciprocal or Robertsonian translocations. J Assist Reprod Genet. 2017;34(11):1483-1492. doi:10.1007/s10815-017-1009-0

76. Dekel-Naftali M, Aviram-Goldring A, Litmanovitch T, et al. Chromosomal integrity of human preimplantation embryos at different days post fertilization. J Assist Reprod Genet. 2013;30 (5):633-648. doi:10.1007/s10815-013-9988-y

77. Fragouli E, Alfarawati S, Spath K, et al. The origin and impact of embryonic aneuploidy. Hum Genet. 2013;132(9):1001-1013. doi:10.1007/s00439-013-1309-0

78. McCoy RC, Demko ZP, Ryan A, et al. Evidence of selection against complex mitotic-origin aneuploidy during preimplantation development. PLOS Genetics. 2015;11(10):e1005601. doi:10.1371/ journal.pgen.1005601
The Application of Clinical Genetics

\section{Publish your work in this journal}

The Application of Clinical Genetics is an international, peerreviewed open access journal that welcomes laboratory and clinical findings in the field of human genetics. Specific topics include: Population genetics; Functional genetics; Natural history of genetic disease; Management of genetic disease; Mechanisms of genetic disease;

\section{Dovepress}

Counselling and ethical issues; Animal models; Pharmacogenetics Prenatal diagnosis; Dysmorphology. The manuscript management system is completely online and includes a very quick and fair peerreview system, which is all easy to use. Visit http://www.dovepress. com/testimonials.php to read real quotes from published authors. 